عدد خاص بالمؤتمر الدولي السادس

8-6 فبراير 2021 بعنوان:

مقومات تطبيق منظومة التعليم الرقمي وآليات

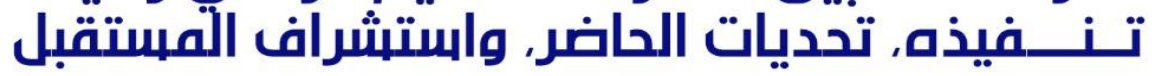

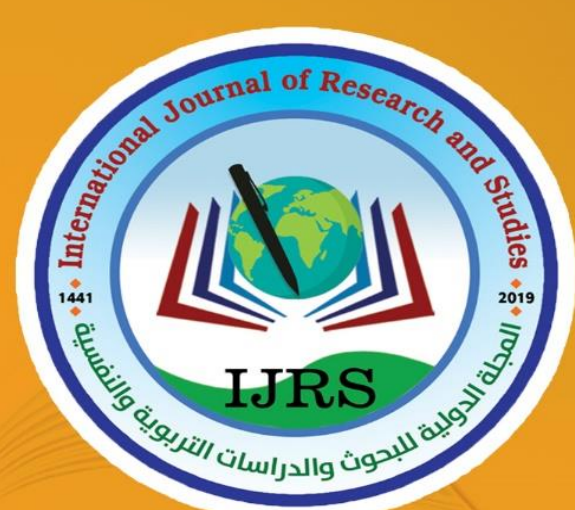

International Journal of Educational and Psychological Research and Studies

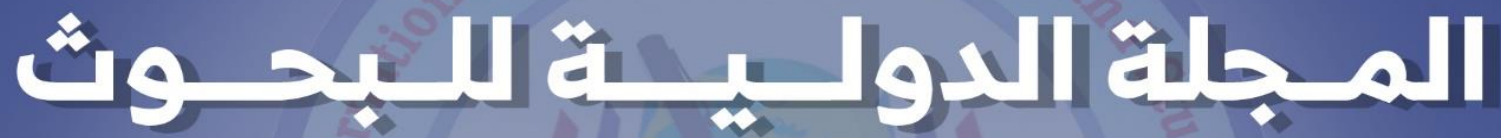

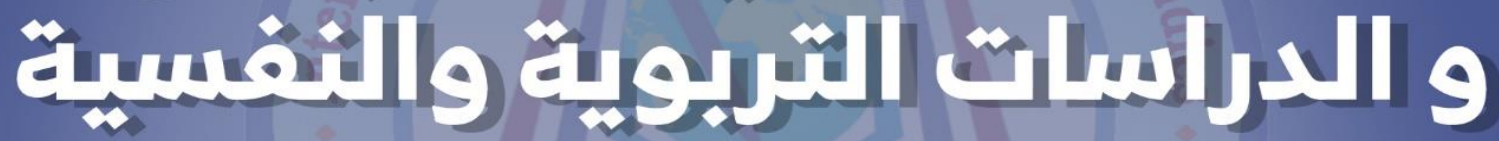 (ISRS)
}

\author{
Liser \\ تصـدرها أكاديميــــة رواد التميز \\ اللتعليم والتدريب والاستشارات
}

The Online 15

$55 \Pi:$

1273 


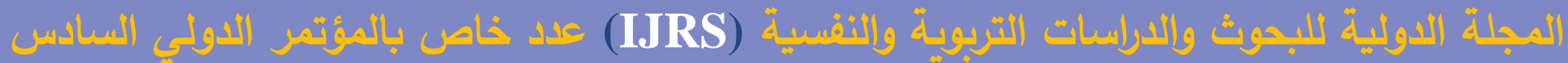

أ.د. راندا مصطفي الديب _ أ. زينب سميح رمضان إبراهيم ، (برنامج قائم علي محفزات الألعاب الرقمية لتنمية حب الاستطلاع).

برنامج قائم علي محفزات الألعاب الرقمية لتنمية حب الاستطلاع المعرفي لأطفال الروضة. إعداد:

أ. زينب سميح رمضان إبراهيم.

باحثة دكتوراه بقسم المناهج وطرق التدريس.

كلية التربية، جامعة كفر الثيخ.
أ.د. - راندا مصطفي الديب.

أستاذ أصول تربية الطفل. كلية التربيةن جامعة طنطا.

مقدم للمؤتمر الدولي السادس لتطوير التعليم العربي، تحت رعاية أكاديمية رواد التميز للتعليم والتدريب والاستشارات، والدجلة الدولية للبحوث والدراسات التربوية والنفسية(IJRS) والمجلة الدولية لبحوث ودراسات

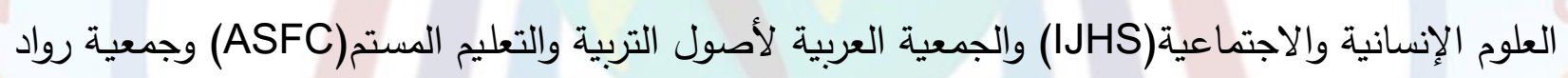
(PEGS) التميز للتمية المستدامة(عطاء ومشاركة)

تحت شعار: (نحو رؤية علمية ناجعة لبناء منظومة التعليم الرقمي).

بعنوان: مقومات تطبيق منظومة التعليم الرقمي، وآليات تنفيذه(تحديات الحاضر، واستثراف (المستقبل).

المنعقد بالقاعة الرئيسية بأكاديمية رواد التميز للتعليم والتدريب والاستثارات، وعبر برنامج الزووم أيام (السبت

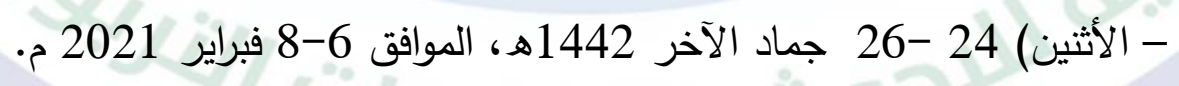




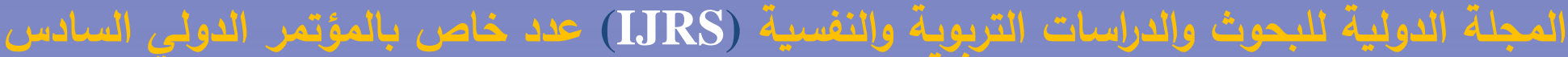

أ.د. راندا مصطفي الديب ـ أ. زينب سميح رمضان إبراهيم ، (برنامج قائم علي محفزات الألعاب الرقمية لتنمية حب الاستطلاع).

\section{مستخلص البحث.}

برنامج قائم علي محفزات الألعاب الرقمية لتنمية حب الاستطلاع المعرفي لأطفال الروضة

الههف من البحث: معرفة فاعلية برنامج قائم علي محفزات الألعاب الرقمية في تتمية حب الاستطلاع

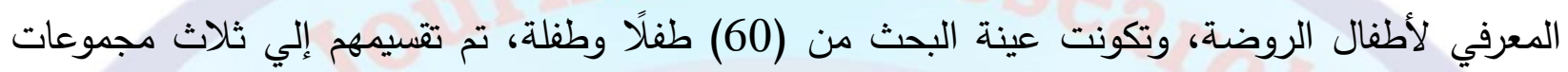

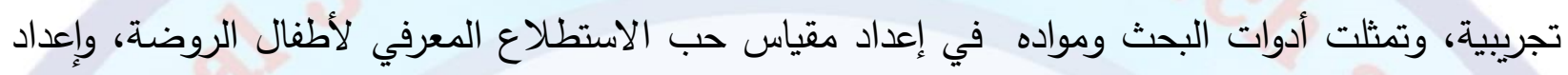

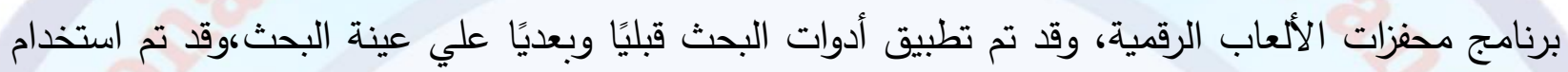
المنهج الوصفي التحليلي والمنهج شبه التجريبي من أجل رصد الدرجات ومعالجتها إحصائياً.

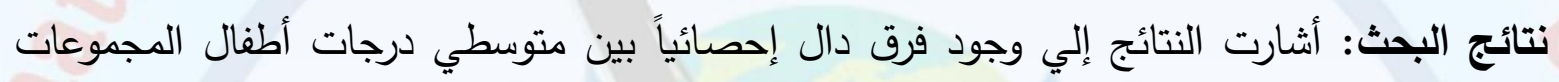

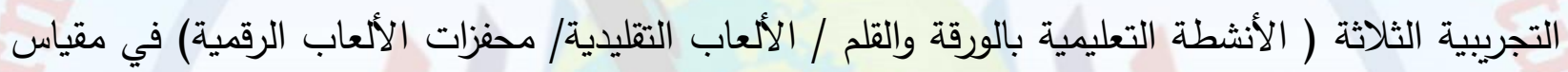
حب الاستطلاع المعرفي لأطفال الروضة ترجع إلى الأثر الأساسي لمحفزات الألعاب الرقمية في البرنامج المقدم لهم.

كلمات مفتاحية: (برنامج، محفزات الألعاب الرقمية، تمية، حب الاستطلاع المعرفي،أطفال الروضة).

\section{Abstract}

Research title: A program based on digital game incentives to develop cognitive curiosity for Kindergarten children

The aim of the research: Knowing the effectiveness of a program based on digital game incentives in developing cognitive curiosity for kindergarten children. The research sample consisted of (60) children and girls, who were divided into three experimental groups, and the research tools and materials were represented in the preparation of the cognitive curiosity scale for kindergarten children, and the preparation of the digital game incentives program The research tools were applied before and after the research sample, and the descriptive analytical approach and the quasi-experimental approach were used in order to monitor the scores and treat them statistically.

Research results: The results indicated that there was a statistically significant difference between the mean scores of the children of the three experimental groups (paper-and-pencil educational activities / traditional games / 


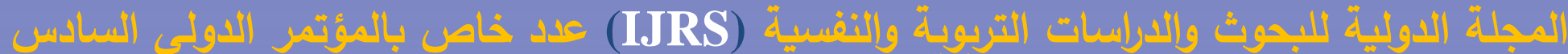

أ.د. راندا مصطفي الديب ـ أ. زينب سميح رمضان إبراهيم ، (برنامج قائم علي محفزات الألعاب الرقمية لتنمية حب الاستطلاع).

digital game incentives) in the cognitive curiosity scale for kindergarten children due to the main effect of digital game incentives in the program presented to them.

Key words: program - digital game incentives - development - Cognitive curiosity - Kindergarten children.

\section{برنامج قائم علي محفزات الألعاب الرقمية لتنمية حب الاستطلاع المعرفي لأطفال الروضة.} مقدمة.

تعد مرحلة رياض الأطفال من أهم المراحل العمرية في حياة الفرد وأكثرها تأثيرًا في مستقبله، لأنها

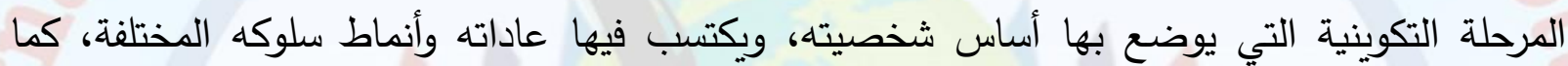

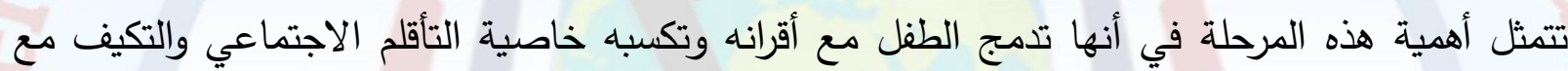
البيئة المحيطة(القحطاني، 2019، 89).

وتتميز شخصية الأطفال بمجموعة من الخصائص والسمات الإيجابية القابلة للنمو من خلال المرور بالتجارب التربوية والتعليمية المختلفة التي تخاطب منافذ التعلم لديهم، وبقدر ما يوفر النظام التربوي من من بيئات صالحة للتعلم والنمو، ويساهم في تعليم الأطفال ورعايتهم والاستثمار فيهم تتحقق لنا النوعية المتميزة

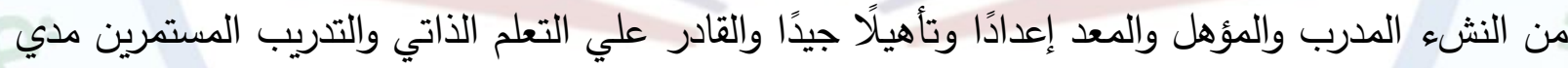
الحياة والمنفتح علي غيره بمرونة والتفاعل مع محيطه وبيئته بإيجابية، والذي يتميز بالفضول العلمي

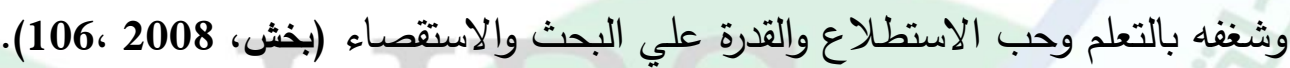
هذا ويعد حب الاستطلاع أحد مهارات القرن الحادي والعشرين ،ولم يكن حب الاستطلاع أكثر أهية مما هو عليه الآن في هذا العصر الذي يتسم بالتغيرات المتلاحقة التي تتطلب نوعية من الأفراد تمتلك العديد من المهارات الأساسية والضرورية للتعامل مع معطيات هذا العصر وتحدياته، ويعد حب الاستطلاع أحد وسائل التوافق مع هذه التغيرات في عالم أصبح كقرية صغيرة، فعن طريقه يتمكن المتعلم من ملاحقة هذه التغيرات، حيث أنه يثير التعلم المستمر، فيساهم في جودة الحياة وفي زيادة رأس المال المعرفي للأفراد 


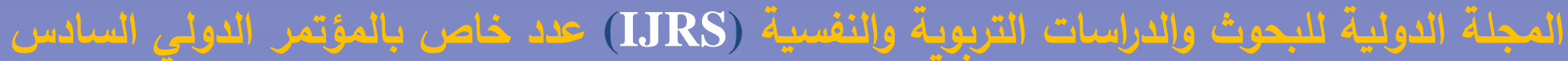

أ.د. راندا مصطفي الديب _ أ. زينب سميح رمضان إبراهيم ، (برنامج قائم علي محفزات الألعاب الرقمية لتنمية حب الاستطلاع).

لاسيما وأن المقررات والمناهج الدراسية مازالت عاجزة عن ملاحقة هذه التغيرات (رحاب خليفة،2016،

هذا وتعد بيئات التعلم الإككترني القائمة علي محفزات الألعاب الرقمية من الإستراتيجيات التعليمية التي نالت اهتمام كثير من التربوين في مجالات مختلفة ومنها مجال رياض الأطفال - وأيضاً - يمكن استخدامها في تتمية حب الاستطلاع المعرفي لدي أطفال الروضة، حيث إنه يشكل دافعًا للأطفال نحو تحقيق أهدافهم بواسطة استكثاف المثيرات البيئية ومعالجتها، ومما يزيد من ضرورة الاهتمام بحب الاستطلاع المعرفي في مرحلة الروضة أن الطفل الذي يبدي سلوكًا معينًا في سن الخامسة والسادسة يمكن أن يبدي نفس السلوك في سن الحادية عشر، فهناك نوعية من الاستمرارية في السلوك الابتكاري وحب الاستطلاع المعرفي، والاهتمام بهذه النوعية من السلوكيات في تلك المرحلة له دور إيجابي في المراحل العمرية اللاحقة (القضاة، 2013، 31).

وبالرغم من الأهمية التربوية والمزايا العديدة للألعاب الرقمية، إلا أنه ما زال العديد من الآباء والأمهات، بل حتي المربين يخفقون في فهم ماهية اللعب وضرورته الحيوية بالنسبة للطفل، إذ يعدونه سلوكًا فارغًا من أي محتوي وظيفي، وعائقاً أمام التعليم والتعلم، وقد غاب عنهم أنه أول بوابة يلجأ إليها

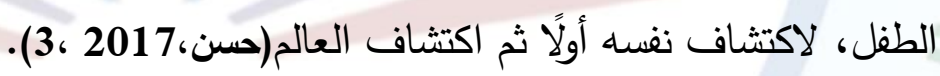
وتري الباحثتان ضرورة البحث والدراسة في العوامل التي تزيد من اقبال الأطفال علي التعليم والتعلم، فقد أصبح شعور الأطفال بالملل والفتور ظاهرة ولعل أحد أسبابها قصور أساليب وطرق التعليم والتعلم عن اشباع رغبات هؤلاء الأطفال وعدم تلبيتها حاجاتهم وعدم مراعاتها تفضيلاتهم وعدم مناسبتها لمستوي حب الاستطلاع المعرفي لديهم، وهذا يستوجب ضرورة توافر برامج تعليمية إلكترونية تتناسب مع مستويات حب الاستطلاع المعرفي والكثف عن أثرها. 


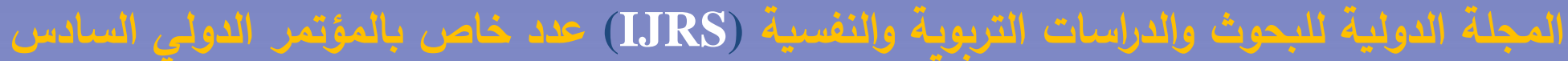

أ.د. راندا مصطفي الديب _ أ. زينب سميح رمضان إبراهيم ، (برنامج قائم علي محفزات الألعاب الرقمية لتنمية حب الاستطلاع).

\section{الإحساس بالمشكلة.}

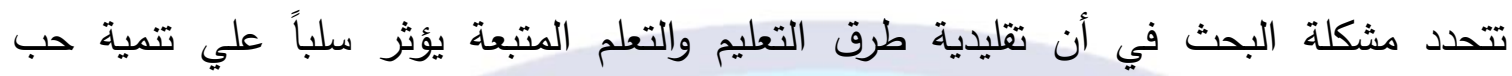
الاستطلاع المعرفي لدى أطفال الروضة وهو ما يفرض علينا تبني مداخل وطرق واستراتيجيات تعليم وتعلم جديدة يمكن أن تسهم في تتمية حب الاستطلاع المعرفي لديهم، ومحفزات الألعاب الرقمية يمكن أن تساهم بشكل كبير في تتمية حب الاستطلاع المعرفي لاى أطفال الروضة؛ لأنهم يستطيعوا أن يستعينوا بمحزات الألعاب الرقمية في أثناء عملية تعلمهم.

ومن هنا جاءت الحاجة إلى القيام ببحث يهدف إلى استخدام محفزات الألعاب الرقمية في تتمية حب الاستطلاع المعرفي لأطفال الروضة، وهذا ما أكدت عليه دراسة (شنودة، وعبدالكريم، 2020) عن أهية الدمج بين التعليم التقليدي والتعليم الإكتروني باستخدام محفزات الألعاب الرقمية، ويمكن تصديد مشكلة البحث في السؤال الرئيس الآتي: ما فاعلية برنامج قائم علي محفزات الألعاب الرقمية في تنمية حب لإنب الاستطلاع المعرفي لأطفال الروضة؟ ويتفرع من السؤال الرئيس الأسئلة الفرعية الآتية:

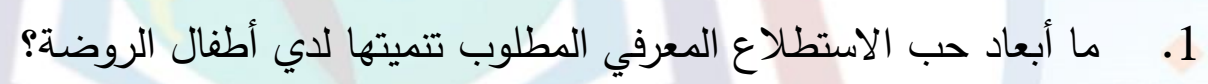
2.2 ما معايير تصميم برنامج قائم علي محفزات الألعاب الرقمية في تتمية حب الاستطلاع المعرفي لأطفال الروضة مانج ماني

3. م ما فاعلية برنامج قائم علي محفزات الألعاب الرقمية في تتمية حب الاستطلاع المعرفي لأطفال الروضة؟

\section{فرض البحث: يسعي البحث الحالي للتحقق من الفروض التالية:}

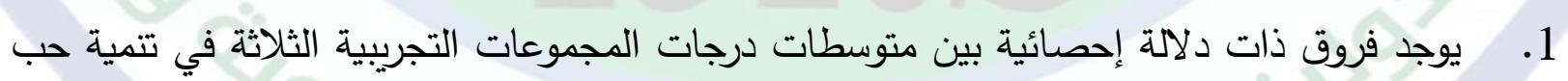
الاستطلاع المعرفي لصالح المجموعة التجريبية الخاصة بالأنشطة التعليمية بالورقة والقلم.

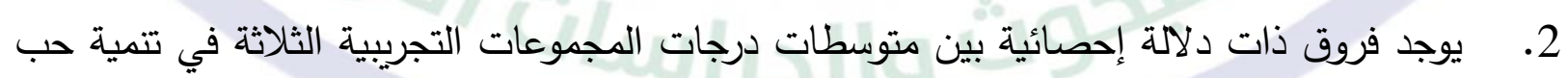
الاستطلاع المعرفي لصالح المجموعة التجريبية الخاصة بالألعاب التقليدية. 


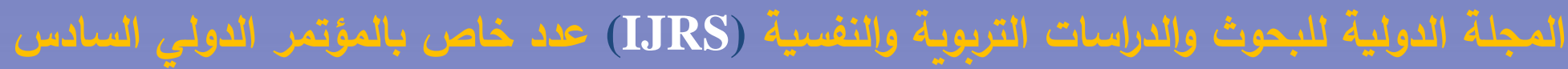

أ.د. راندا مصطفي الديب _ أ. زبنب سميح رمضان إبراهيم ، (برنامج قائم علي محفزات الألعاب الرقمية لتنمية حب الاستطلاع).

3. يوجد فروق ذات دلالة إحصائية بين متوسطات درجات المجموعات التجربية الثلاثة في تتمية حب الاستطلاع المعرفي لصالح المجموعة التجريبية الخاصة بمحفزات الألعاب الرقمية.

هدف البحث: يهذف البحث الحالي إلي التحقق من: فاعلية برنامج قائم علي محفزات الألعاب الرقمية في تتمية حب الاستطلاع المعرفي لأطفال الروضة. أهمية البحث: وتتمثل فيما يلي:-

1. إلقاء الضوء علي أهمية استخدام محفزات الألعاب الرقمية في مجال التعليم والتعلم لدي المسئولين عن العملية التعليمية في مرحلة رياض الأطفال.

2. إلقاء الضوء علي أبعاد حب الاستطلاع المعرفي وأهمية تنميته في مجال التعليم والتعلم لدي المسئولين عن العملية التعليمية في مرحلة رياض الأطفال. 3. الإسهام في زيادة تعلم وتعليم الأطفال من خلال محفزات الألعاب الرقمية عن طريق توظيف معلمات الروضة لمبادئ هذه المحفزات داخل بيئات التعلم لتحقيق المشاركة والتفاعل في الأنشطة وتتمية حب الاستطلاع المعرفي لدي الأطفال.

4. تقديم برنامج قائم علي محفزات الألعاب الرقمية في تنمية حب الاستطلاع المعرفي لأطفال الروضة. حدود البحث: وكاتت كما يلي:-

1. الأطفال، وتم توزيعهم بطريقة عشوائية إلي ثلاث مجموعات (تجريبية) كالتالي: • المجموعة التجرببية الأولى تكونت من (20) طفلًا واعتمدت علي الأنشطة التعليمية. • المجموعة التجريبية الثانية تكونت من (20) طفلًا واعتمدت علي تطبيق الألعاب التقليدية. " المجموعة التجريبية الثالثة تكونت من (20) طفلاً واعتمدت علي محفزات الألعاب الرقمية.

2. الحدود المكانية: المستوي الثاني من مرحلة رياض الأطفال بمدرسة سمارت الخاصة للغات بطنطا إدارة شرق طنطا التعليمية - محافظة الغربية. 


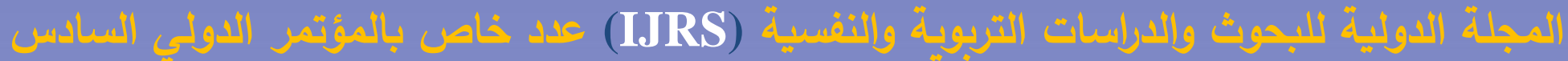

أ.د. راندا مصطفي الايب ـ أ. زبنب سميح رمضان إبراهيم ، (برنامج قائم علي محفزات الألعاب الرقمية لتنمية صب الاستطلاع).

$$
\text { 4. الحدود الزمنية: في الفترة من } 2020 \text { / } 2020 \text { إلي } 25 \text { / } 2020 \text { / }
$$

5. الحدود الموضوعية: اقتصر البحث علي محفز ات الألعاب الرقمية و حب الاستطلاع المعرفي.

مصطلحات البحث: وسوف تعرف الباحثتان مصطلحات البحث إجرائيًا علي النحو التالي:

1-محفزات الألعاب الرقمية: هي تصميم وتوظيف عناصر اللعبة في بيئات التعلم لتطوير المفاهيم والمهارات وحب الاستطلاع المعرفي من خلال المشاركة والتفاعل عوضًا عن التلقين والتوجيه المباشر بالاستثارة لجعل التعلم أكثر جاذبية.

2-حب الاستطلاع المعرفي: هو استجابة للمشيرات المعقدة والغامضة والجديدة بالسؤال عنها والتحرك نحوها محاولًا استكثافها ومعرفة المزيد عنها.

الإطار النظري والدراسات السابقة. وقسم الإطار النظري إلي المحاور التالية.

المحور الأول: محفزات الألعاب الرقمية (digital game incentives) وسوف يتتاول هذا

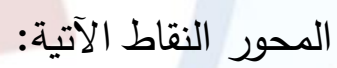

أولًا: مفهوم محفزات الألعاب الرقمية: الألعاب الرقمية مصطلح جديد مشتق من كلمة (Game) أي اللعب، أو اللعبة، يعرف كذلك باسم (Ludification) ويترجم عربيًا بكلمة الألعاب التتافسية(المـلاح،

وفهيم،2016،93).

ولقد تعددت التعريفات الخاصة بمحفزات الألعاب الرقمية حيث يعرفها تيدرتج وآخرون (Deterding,etal,2011,28-39) زيشرمان وسينجهام (Zicherman\&Cunningham,2011) بأنها استخدام ألعاب التفكير وتقنيات اللعبة

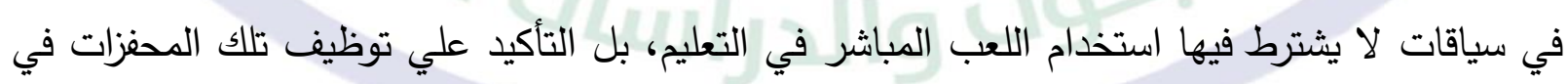
توصيل المفاهيم والسلوكيات المطلوب إكسابها للتتاميذ بشكل غير مباشر مثل حل المشكلات. 


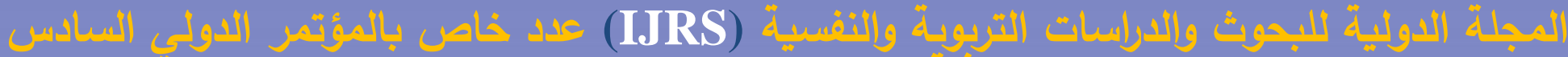

أ.د. راندا مصطفي الديب _ أ. زينب سميح رمضان إبراهيم ، (برنامج قائم علي محفزات الألعاب الرقمية لتنمية حب الاستطلاع).

كما أنها تعني استخدام عناصر تصميم اللعب بمعني محفزات القيام به واستخدامها في سياقات أخرى غير اللعب كتعلم محتوى، أو تتمية حب الاستطلاع المعرفي وغيرها، وذلك لتعزيز مشاركة المستخدمين (Smith-Robbins, S,2011, 58) وهي ألعاب تثير خيال المتعلمين وتتمي تفكيرهم وصولًا للفوز باللعبة وتتمي سلوك المتعلمين وقدراتهم العقلية والجسمية والوجدانية(عبدالمولي،2015). وقد أوضح مصطفي القايا (2015) أن مصطلح محفزات الألعاب الرقمية يشير إلي اتجاه تعليمي ومنحني تطبيقي جيد، يهتم بتحفيز المتعلمين للتعلم باستخدام عناصر الألعاب من فكر وتقنيات في بيئات التعلم، وذلك بهدف تحقيق أقصي قدر من المتعة والمشاركة من خلال جذب اهتمام المتعلمين والتأثير علي سلوكهم مع التركيز علي المهام التعليمية والمعرفية المفيدة. وهي نهج فعال لإحداث التغيير الإيجابي في سلوك المتعلمين والموقف التعليمي؛ لتحسين دوافعهم والمشاركة ونتائج التغيير لها طبيعية وتؤثر علي نتائج الطلاب وفهم المحتوي التعليمي وتهيئة الظروف لتفعيل عملية التعلم(حسن،2017،29). هذا وتقوم محفزات الألعاب الرقمية علي عملية تحديد العناصر التي تتكون منها اللعبة والتي تجعل تلك الألعاب ممتعة ومحفزة للأطفال لمواصلة اللعب واستخدام تلك العناصر نفسها في سياق غير اللعبة للتأثير علي السلوك في سياقات تعليمية. وتعرف محفزات الألعاب الرقمية بأنها هي استخدام مبادئ وآليات الألعاب من فكر وتقنيات اللعبة في سياق تعليمي لإشراك المتعلمين في حل المشكلات وزيادة دافعيتهم للتعلم (أحمد $\cdot(23-22 ، 2017$, وتعرفها الباحثتان إجرائيا بأنها هي: تصميم وتوظيف عناصر اللعبة في بيئات التعلم لتطوير المفاهيم والمهارات وحب الاستطلاع المعرفي من خلال المشاركة والتفاعل عوضًا عن التلقين والتوجيه المباشر بالاستثارة لجعل التعلم أكثر جاذبية.

ومن خلال التعريفات السابقة لمحفزات الألعاب الرقمية تري الباحثتان أنها:

$$
\text { وسيط تعليمي يعتمد علي التسلية والترفيه. }
$$

ألعاب تثير خيال المتعلمين وتتحدي قدراتهم وتتمي تفكيرهم وصولًا للفوز باللعبة. 


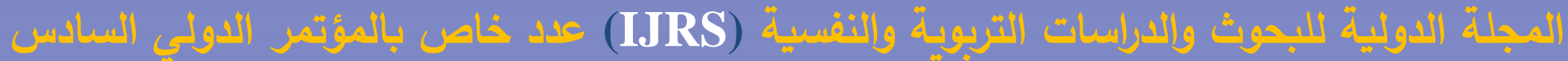

أ.د. راندا مصطفي الديب _ أ. زينب سميح رمضان إبراهيم ، (برنامج قائم علي محفزات الألعاب الرقمية لتنمية حب الاستطلاع).

• ألعاب تتمي سلوك المتعلمين وقدراتهم العقلية والجسمية والوجدانية.

يحكم كل لعبة مجموعة من القوانين والقواعد علي اللاعبين المتعمين اتباعها.

يعد التعليم والتعليم باستخدام محفزات الألعاب الرقمية من أبرز الإستراتيجيات التعليمية التي تراعي

\section{سيكولوجية المتعلم.}

ثانيًا: مميزات استخدام محفزات الألعاب الرقمية في التعليم والتعلم.

1.تزيد دافعية التعلم لدي الأطفال وتحفيزهم وخلق أبعاد جديدة لعملية التعلم، وإكسابهم سلوكيات تعليمية

جديدة، مع اثبات الذات من خلال اللعب وتحقيق الهدف دون الاستعانة بالآخرين.

2. تساعد المتعلم في التخلص من الضغوط النفسية التي تقع عليه من الممارسات التربوية، أو التنشئة الاجتماعية، مثل الخجل والانطواء، وتعطي للمتعلم الحرية في ممارسة نشاطه والمشاركة في اتخاذ القرار المناسب مبتعدًا عن الأسلوب التقليدي المتضمن للأوامر والسلطة من قبل المعلم.

3. التحرر من الخصومة والنزاع، وتقلل من المشاعر السلبية التي يواجهها الأطفال في الأشكال التقليدية

للتعليم لأنها تعتمد على محفزات (حسن ،2017 233).

4. تعد من أكثر الوسائل التي تثير التفكير لدي المتعلم وتعمل علي زيادة نموه العقلي خاصة التفكير الإبداعي، كما أنها تستخدم مؤثرات سمعية وبصرية لذلك فهي تستخدم أكثر من حاسة لدي الطفل مما يجعل التعلم من خلالها أبقي أثرًا وأكثر تأثيرًا.

5. ممتعة ومن أكثر الوسائل التعليمية تشويقًا وجذبًا، وغير مرتبطة بزمن معين؛ فيستطيع المتعلم اللعب في

أي وقت يرغب ولأي مدة يريدها، ونضمن مع إمكانية تكرار برامج المحفزات تعلم طفل الروضة حتي مرحلة التمكن والاتقان.

كما أنها تتيح إمكانية تقسيم المعلومات إلي خطوات صغيرة في شكل أنشطة تتطلب استجابة من المتعلم وتعطي تغذية راجعة فورية، مما يركز علي الهدف التعليمي ويدفع المتعلم لمواصلة اللعب(العمري ، 2015) ومواصلة تعلمه؛ وهذا يتقق مع مبادئ النظرية السلوكية. 


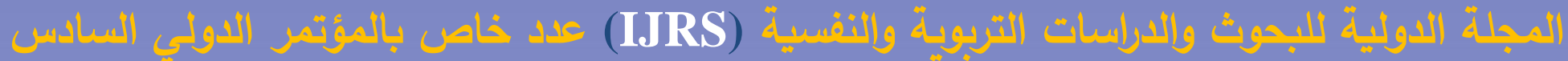

أ.د. راندا مصطفي الديب _ أ. زبنب سميح رمضان إبراهيم ، (برنامج قائم علي محفزات الألعاب الرقمية لتنمية حب الاستطلاع).

6. تعمل علي ادخال البهجة والسرور لدي المتعلم لما فيها من حركة ومرح وامتاع وتسلية، كما تجعله يتقبل الهزيمة بروح رياضية، كما تساعد علي جعل المعلومات أقل عرضة للنسيان وأبقي أثرًا في ذهن المتعلم، ويمكن تقسيم المتعلمين إلي مجموعات صغيرة، ويكون لكل مجموعة قائد مما يؤدي إلي نمو عنصر التعاون والمشاركة بين أفراد المجموعة الواحدة ونمو عنصر المنافسة بين المجموعات المختلفة بالإضافة إلي اكتثاف الثخصيات والمواهب القيادية بين المتعلمين في الصف وقاعات النشاط. 7.تدعم الأطفال بمهارات القرن الواحد والعشرين وإدارة المهارات الحياتية وإدارة قدراتهم، وذلك بإعادة التفكير في بناء المناهج والبرامج بما يتناسب مع خصائصهم(Karl Kapp,2012,15). وتري الباحثتان أن مع المميزات المذكورة فإن كثرة استخدام الألعاب التعليمية الإكترونية بدون ترشيد وضبط لله مخاطر صحية وسلوكية علي الأطفال. ثالثًا: "سمات محفزات الألعاب الرقمية": توفر الألعاب الرقمية بيئة تعلم فعالة ليست - فقط - لأنها مدتعة ولكن لأنها تغدر اللاعبين في أجوائها وتتطلب منهم اتخاذ قرارات متكررة ومهمة، كما أن هذه الألعاب لها أهداف محددة، وتتكيف مع كل لاعب علي حدة، ولكي تكون بيئة التعلم فعالة فلابد أن تتوافر فيها سبع متطلبات أساسية وهي أن تكون قادرة علي توفير كثافة عالية من التفاعل والتغذية الراجعة، وأن تكون ذات أهداف محددة وإجراءات ثابتة ، كما يجب أن تكون تحفيزية، وتوفر شعور مستمر بالتحدي، ولا تكون صعبة للغاية فتؤدي إلي الاحباط ولا سهلة إلي الغاية فتسبب الملل، وتوفر احساس بالجاذبية تجاه المهمة المحددة، وتوفر الأدوات المناسبة التي تتلاءم مع المهمة، وتتجنب الانحرافات التي تدمر الخبرات الذاتية، كما أن Kasvi ( أللعاب الرقمية قادرة علي تلبية جميع هذه المتطلبات، وأنها أفضل من معظم وسائل التعلم الأخرى $\cdot(, 2000$ وتتميز محفزات الألعاب الرقمية بسمات تميزها عن الوسائل التعليمية الأخرى وعن أي من الألعاب الترفيهية، ومن هذه الخصائص أنها: 


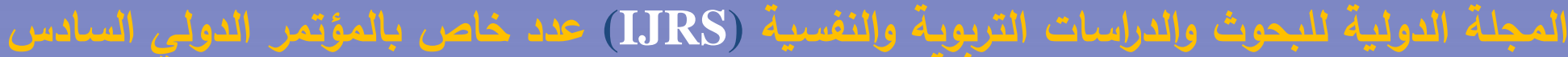

أ.د. راندا مصطفي الديب _ أ. زبنب سميح رمضان إبراهيم ، (برنامج قائم علي محفزات الألعاب الرقمية لتنمية حب الاستطلاع).

1) تحفيزيـة: حيث أن الألعاب الرقمية ممتعة ومرحة ومتحدية وتكافئ من يقوم بها؛ فقد أثبتت عدة بحوث أن المرح والمتعة عناصر مهمة في عملية التعلم حيث يكون المتعلمين أكثر استرخاء ودافعية واستعداد للتعلم، وطبقا لنظرية الدوافع الذاتية لمالون (1980) أن التحدي والخيال والقدرة علي التحكم وحب الاستطلاع والتعاون والمنافسة من أهم العناصر التي تجعل ممارسة تلك الألعاب ممتعة وتحفيزية وتعزز دوافع اللاعبين باستمرار • 2) تجربية: الألعاب بطبيعتها تجريبية فمن يمارس هذه الألعاب يستخدم حواسه المتعددة في كل عمل أو تفاعل داخل اللعبة وهناك رد فعل وهو التغذية الراجعة السريعة الفورية ويتم من خلال اختبار البدائل ويتعلم المستخدم لتلك الألعاب من خلال النتائج.

3) معرفية: يمكن أن تؤدي اللعبة الرقمية المعدة جيدًا دورًا إيجابيا من خلال سياق شبه واقعي حقيقي في اكساب الأفراد عديد من المعارف والمهارات، فكثير من الألعاب الرقمية تتطلب عشرات الساعات، أو أكثر في لعبها، ويحتاج اللاعبين فيها إلي اكتساب مهارات جديدة ومتعددة والاتصال أو التشارك مع لاعبين آخرين داخل أو خارج اللعبة. كما يقوم اللاعبين بتحليل المعلومات المستقبلة وتطبيق المعرفة المسبقة، والمهارات الرقمية تقدم المطمح لبيئات التعلم المعرفية للمتعلم حيث أن المتعلم يستطيع التجريب والحصول علي التغذية الراجعة علي اقتراحاته واستراتيجياته، وهذه طريقة معرفية جديدة للمتعلمين في طلب المعرفة واكتساب المهارات بطريقة بناءة، كما أن معرفة ماهية المعلومات، أو التقنيات اللازم تطبيقها في مواقف معينة يؤدي في كثير من الأحيان إلي مزيد من النجاح وخاصة حل المشكلات التي تتضمن غالبًا تفاعلات كثيرة خلال اللعبة)

.(Diana Oblinger, 2006

4) بحثية (استقصائية): عند دخول اللاعب في عالم اللعبة فأنه يجب أن يتذكر بعض المعلومات السابقة ويقرر أو يحدد ما هو المطلوب من المعلومات الجديدة وكيفية تطبيقها في الموقف الجديد (الوضع الحالي للعبة) وهؤلاء الأطفال الذين يلعبون بتلك الألعاب عادة ما يحتاجون إلي القراءة والبحث عن المعلومات الجديدة من أجل السيطرة علي اللعبة( Jong Morris et al. , 2008 ). 


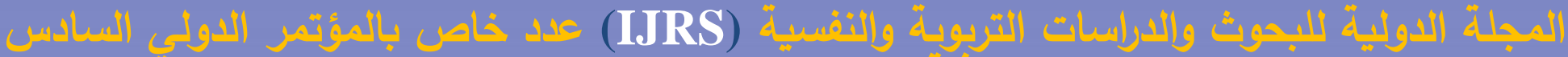

أ.د. راندا مصطفي الديب ـ أ. زينب سميح رمضان إبراهيم ، (برنامج قائم علي محفزات الألعاب الرقمية لتنمية حب الاستطلاع).

5) تثقيفية اجتماعية: تعليم الأطفال لا يعني - فقط - أن نبني تمثيلات في عقولهم ولكن لابد من ادماج

هؤلاء الأطفال في الممارسات الاجتماعية؛ فالمعرفة في حد ذاتها وفقا للمنظور الاجتماعي تتشأ من

الاحتياجات الاجتماعية وترتبط طبيعتها بالظروف الثقافية المحيطة، وبالتالي فأن التعلم ليس مجرد

عملية اتقان الحقائق، أو حتي القيام بالمهارات المعقدة، وهذا يتطلب من المتعلمين تطوير العلاقات

\section{الاجتماعية مع الآخرين( Diana Oblinger , 2006 ) - ( )}

وتعد الألعاب الرقمية بيئات تعلم اجتماعية؛ فالجيل الجديد المستخدم لهذه الألعاب يفضل المنافسة البشرية والمشاركة؛ فالتعلم القائم علي الألعاب يستطيع تهيئة عالم اجتماعي وثقافي أكثر يساعد علي تعلم

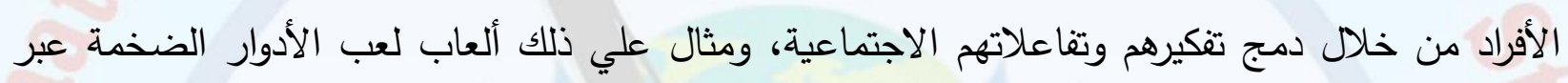
شبكة الانترنت حيث يلتقي اللاعبون عبر الانترنت ويشكلون فريقًا لمناقشة التحديات واكمال المهام وحل

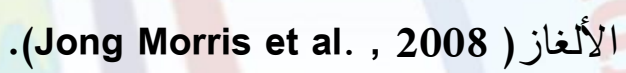

رابعًا: الفرق بين محفزات الألعاب الرقمية وأنواع الألعاب الأخري، وسوف يوضح الجدول رقم (1) هذه الفروق:

جدول (1) الفرق بين محفزات الألعاب الرقمية وأنواع الألعاب الأخري.

\begin{tabular}{|c|c|c|c|c|}
\hline محفز ات الألعاب الرقمية & التعلم القائم علي اللعبة & الألعاب الجادة & الألعاب الإلكن & وجه المقارنة \\
\hline 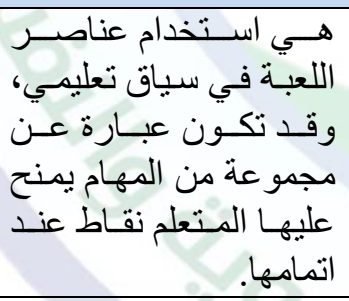 & 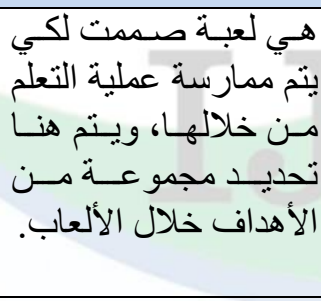 & تعليمة مصــمهة & 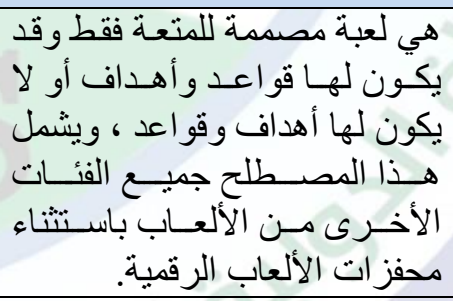 & \\
\hline 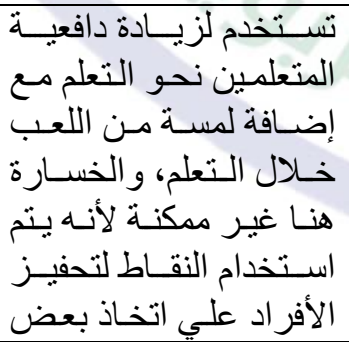 & 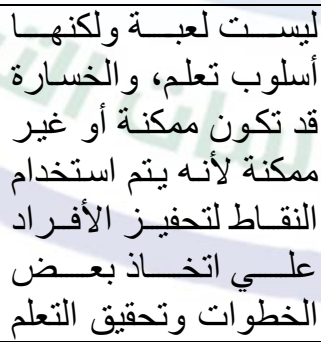 & 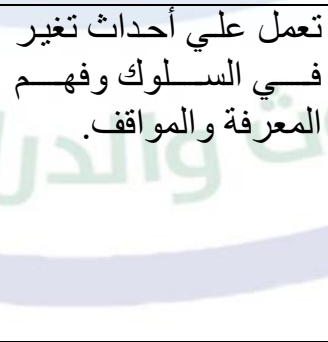 & 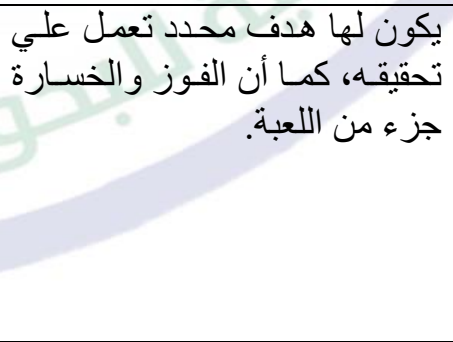 & الهنا \\
\hline
\end{tabular}




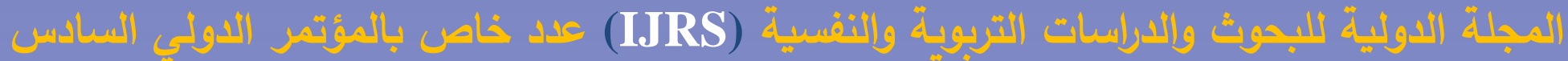

أ.د. راندا مصطفي الديب _ أ. زبنب سميح رمضان إبراهيم ، (برنامج قائم علي محفزات الألعاب الرقمية لتنمية حب الاستطلاع).

\begin{tabular}{|c|c|c|c|c|}
\hline الخطوات وفعل شيء. & في النهاية. & & & \\
\hline 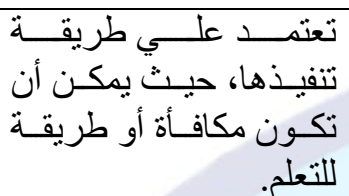 & تستـخلم لتحسين عمليـة & 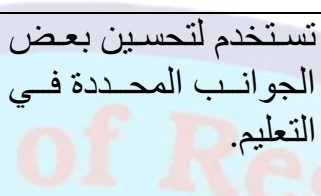 & & 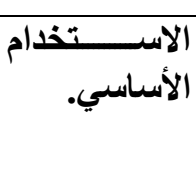 \\
\hline 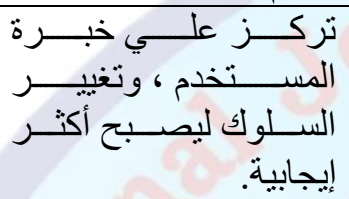 & 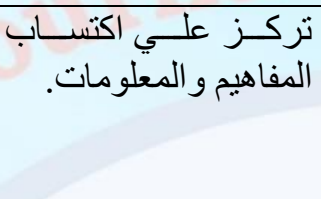 & 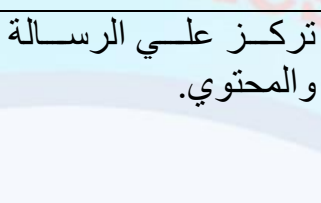 & لعب باللعبة. & التركيز. \\
\hline فــي التعلِّم عـادة مـا يـتم & 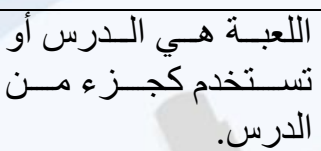 & 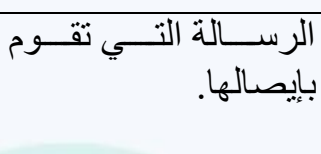 & أساسي. & \\
\hline 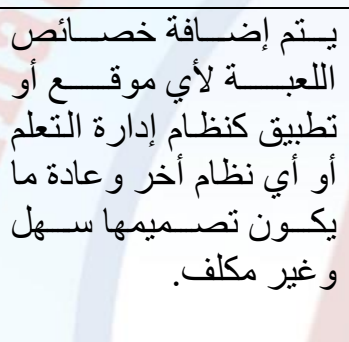 & 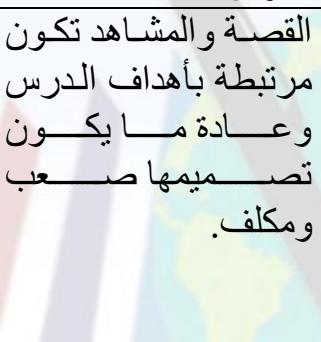 & 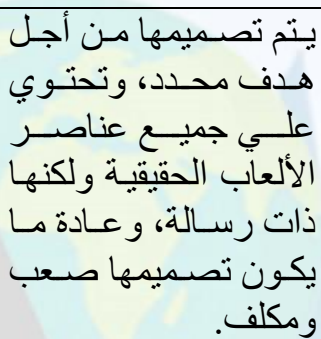 & 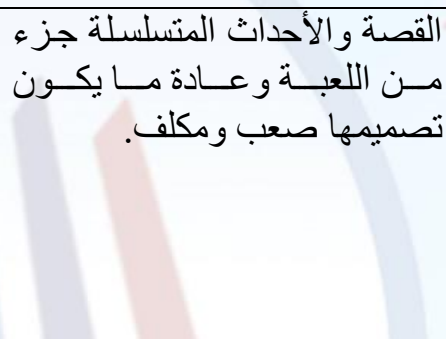 & 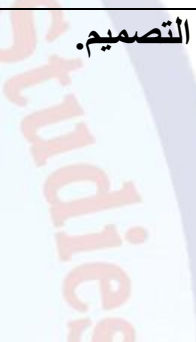 \\
\hline
\end{tabular}

المصدر (تسبيع حسن،2017، 23-25).

المحور الثاني: حب الاستطلاع المعرفي (Cognitive Curiosity) وسوف يتتاول هذا المحور النقاط الآتية:

أولاً: مفهـوم حب الاسـتطلاع المعرفي: تعددت تعريفات حب الاستطلاع المعرفي لدي الفلاسفة والمفكرين وعلمـاء النفس فقد تم تعريفـه بأنـه حاجـة محفزة لمعالجـة المعلومـات، وبأنـه دافع فطري لا يشـبع بالطعـام، أو الشـراب، أو التعزيـز ، ولكنـه يشبع بالحصـول علـي الجـواب والمعرفـة (الثيثـاني، وغباري، 2015، 12).

ويعرفه (الهويدي، 2005) بأنه الرغبة في المزيد من المعرفة وكثرة الأسئلة والبحث عن الإجابات من خلال القراءة والبحث. 


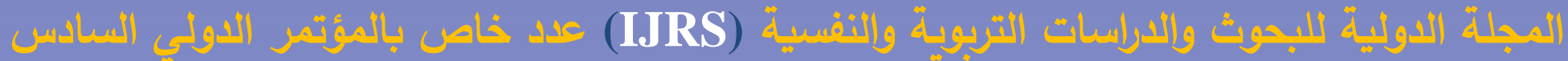

أ.د. راندا مصطفي الديب _ أ. زينب سميح رمضان إبراهيم ، (برنامج قائم علي محفزات الألعاب الرقمية لتنمية حب الاستطلاع).

وتعرفه الباحثتان إجرائيا بأنه استجابة للمثرات المعقدة والغامضة والجديدة بالسؤال عنها والتحرك نحوها محاولا استكثافها ومعرفة المزيد عنها.

\section{ثانيًا: أهمية حب الاستطلاع المعرفي. \\ ل يدفع الطفل لاكتساب المعرفة. ل يشجع الطفل علي التعلم المستمر - ل} ل يشجع الطفل علي البحث واكتشاف كل ما هو جديد. ل يزود الأطفال بثروة من المعلومات المهمة التي تزيد من المعرفة لديهم. ل تنمية المرونة وزيادة الاهتمام والتقتح العقلي والبحث عن الأشياء الجديدة. ل يعمل علي تركيز الانتباه وزيادة الإدراك الحسي، كما أنه ينمي خبرات الطفل الحسية. ل تجعل الأطفال أكثر إيجابية ومشاركة في العملية التعليمية (موسي ،2015، 157).

كما يعتبر حب الاستطلاع المعرفي خطوة أولي نحو الإبداع، وأحد وسائل العملية التعليمية فأي منتجه إبداعي هو نتيجة حب الاستطلاع المعرفي والاستكشاف لدي الفرد المبدع، كما يعد عنصر حاسم في الحياة العقلية والأخلاقية، فعند اكتسابه يمكن أن يصبح سمة لذلك الفرد يمكنه استخدامه في حل المشكلات بحيث يصبح نهج للحياة.

كما يعمل علي تقوية الذكاء من خلال المفاضلة الحكيمة بين الأشياء، وهو نشاط وليست معلومات سلبية متراكمة، وصرح كيلر (Keller) بأهمية الدور الذي يلعبه حب الاستطلاع المعرفي في إثارة الدافعية

والحصول علي الانتباه والمحافظة عليه (Fisher et al, 2000; Amone, M. 2003)

وأيضا يزيد من انتباه الطفل ومن ثم إعطاء الاستجابة المناسبة للمثير، ويعزز من سلوك البحث عن المعلومات (Driscoll,2000) ويشجع علي التكيف ويساعد علي التقيب والاستقاء، ويساعد علي تتمية المرونة وزيادة الاهتمامات والتقتح العقلي والبحث عن الأشياء الجديدة، ويؤدي إلي خفض حالة التوتر 


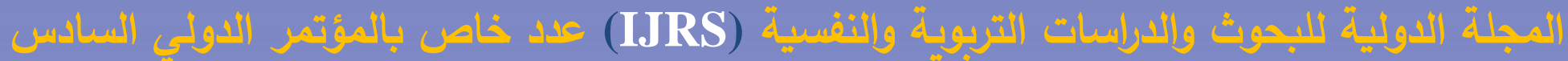

أ.د. راندا مصطفي الديب _ أ. زينب سميح رمضان إبراهيم ، (برنامج قائم علي محفزات الألعاب الرقمية لتنمية حب الاستطلاع).

الناتجة عن زيادة الدافع؛ فعن طريق البحث الهادف المدفوع بحب الاستطلاع يخفض الفرد من حالة التوتر لديه (الشعراوي، 1997، 45).

ثالثًا: أبعاد حب الاستطلاع المعرفي، يتحدد حب الاستطلاع المعرفي من خلال أربعة أبعاد رئيسية وهي:

1- الجدة (Novelty): وتعني الاستجابة للمثيرات المألوفة في تجميع لم يسبق من قبل، وتتمثل الجدة في المثيرات التي تحتوي علي عناصر ، أو صفات جديدة بالنسبة للمتعلم، عندما يتم عرضها عليه تجعله شغوفًا بها، وأن يحاول اكتشاف خصائصها والتعرف عليها، وذلك لأن كل المثيرات تكون جديدة في لحظة ما، وبالتالي لابد أن يكون لكل المثيرات نفس التأثيرات الخاصة في مرحلة ما، لكنها بعد أن تحدث مرة واحدة، أو بعد أن تتكرر عدة مرات تفقد هذه المؤثرات، ويكون ذلك نتيجة التعود علي استجابة لم يسبق تعلمها (السيد، و سلطان، 2015 ، 25$).$

$$
\text { وتوجد أربع أنواع للجدة وهي:- }
$$

أ-الجدة الكاملة: وتعني أن المثير يكون جديدًا فيما يتصل بالخبرة الكاملة للفرد. ب- الجدة قصيرة الأمد: وهي أن المثير يكون جديدًا بالنسبة لمجرد خبرة الفرد الحديثة. ت- الجدة المطلقة: ويقصد بها وجود صفة لم يسبق أن أدركها الفرد من قبل. ث- الجدة النسبية: وهي تعني أن المثيرات مألوفة، ولكن تم عرضها في تجميع لم يسبق من

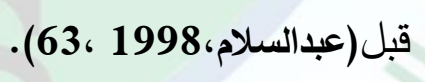

2- عدم التوقع (الفجائية) (Surprisingness): وهي عبارة عن ظهور استجابات لا تتفق مع المثير، أي أنها مثيرات لا يعرفها الفرد وتتطلب استجابة أعمق منه، وذلك عن طريق تحصيل معلومات عنها، وتتطلب منه القدرة علي الانتظار حتي يصل إلى تعريف دقيق ومعقول للشيء، وبالتالي فإن الأشياء التي تشكل حيرة لدى الفرد أفضل من التي لا تحدث عنده الحيرة، لأنه عندما يقدم شيء غير مألوف إلى

\section{4}




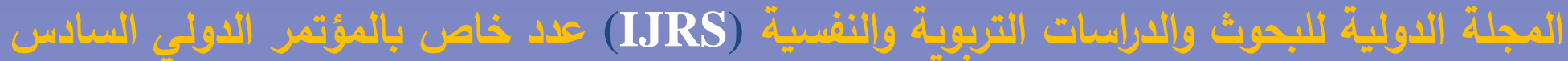

أ.د. راندا مصطفي الديب _ أ. زينب سميع رمضان إبراهيم ، (برنامج قائم علي محفزات الألعاب الرقمية لتنمية حب الاستطلاع).

الفرد فأنه يكون حتما مدفوع إليه أولًا بهدف جمع المعلومات، وثانيًا لاستجلاء الموقف لإزالة وجه الغرابة والغموض عنه (عبدالهادي، 2004 ، 102).

3- التعارض (Incongruity): ويعني عدم اتساق الأجزاء المكونة للمشير، أي المثيرات المخالفة للتوقعات القائمة علي الخبرة السابقة للفرد، وتثير لديه عديد من الأفكار والأسئلة عما هو مقدم إليه وتجعله في مستوي متتاقض، والفرد عندما يواجه تعارضًا، أو تتاقضًا بين مفاهيمه والحقيقة يبدأ في البحث عما يجب أن يكون، وعندما لا يقدر إلي الوصول إلي الحقيقة المتفقة مع مفاهيمه، يقع في حيرة وتناقض يدفعه إلى تحدي الصعوبات ليزيل هذا التناقض(السيد، وسلطان، 2015 ،46). 4- التعقيد (Complexity): ويقصد به الاستجابة للمثيرات المتنوعة. أي تباين العناصر التي تؤدي إلساختلاف المثير كلما إزداد التنوع في المثير يزيد التعقيد، والذي يؤدي بدوره إلى زيادة الصعوبة النسبية في تفير هذا المثير، - وأيضاً - الميل إلي الأشياء المعقدة هو أحد مظاهر حب الاستطلاع المعرفي، ويمكن إثرائه عن طريق طرح الأسئلة المتعدة لكثف الغطاء عن الأشياء الغامضة(عبدالله، 1993

رابعًا: أنواع حب الاستطلاع: ميز برلاين (Berlyn) بين نوعين من أنواع حب الاستطلاع وهما: أـ - حب الاستطلاع الإدراكي:(Perceptual curiosity): وهو الذي يؤدي إلى الإدراك المستمر للمثيرات، فعندما يؤثر مثير ما علي حاسة من حواس الإنسان تصدر عنه استجابة نتيجة وجود مثير داخلي يدفعه وهو حب الاستطلاع، إلا أنه مع استمرار المثير فان حب الاستطلاع الإدراكي يتضاءل نتيجة التعود. ب- حب الاستطلاع المعرفي: ويتمثل في الرغبة في المعرفة ونتيجة لإشباع هذه الرغبة تتخفض حالة التوتر الموجودة لدي الفرد والتي هي وليدة الرغبة في المعرفة (برلاين ، 1993 ،327).

ويشير كولينز (Collin,s) إلي أن حب الاستطلاع يتكون من ثلاث مكونات وهي: حب الاستطلاع المعرفي. 


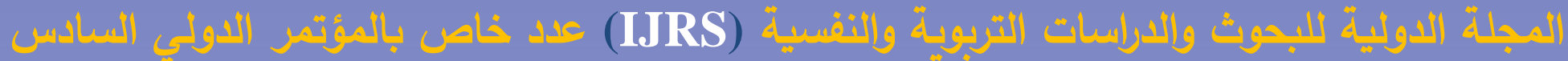

أ.د. راندا مصطفي الديب _ أ. زبنب سميح رمضان إبراهيم ، (برنامج قائم علي محفزات الألعاب الرقمية لتنمية حب الاستطلاع).

\section{• حب الاستطلاع الإدراكي.

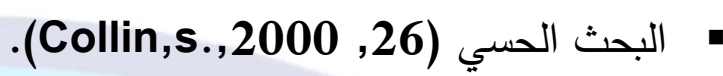

وتري الباحثتان أن حب الاستطلاع المعرفي يتعلق بالرغبة في البحث ومحاولة اكتساب المعرفة ويتضح من خلال رغبة الطفل في القراءة والاستفسار عن الأشياء وطرح الأسئلة، أما حب الاستطلاع الإدراكي فهو يتعلق بميل الطفل للانتباه والإدراك لبعض المثيرات الموجودة في بيئته ويتضح من خلال تفحص الطفل الأشكال المعدة والصور الغريبة أكثر من تفحصه للأشكال الواضحة البسيطة.

خامسًا: حب الاستطلاع المعرفي وأطفال الروضة: يفترض علماء النفس المعرفي أن حب الاستطلاع ظاهرة نمائية معرفية، ويترتب علي ذلك أن حب الاستطلاع ينمو ويتطور مع العمر ، وتسهم الظروف البيئية في تطوره وبلورته علي صورة أداءات وبحث وتقص ونشاطات ذهنية أخري مرتبطة به (حسن ،1992،

ويظهر الطفل المحب للاستطلاع أداءات تصنف بأنها أداءات استطلاعية معرفية، وتحدد وفقها درجات حبه للاستطلاع المعرفي، ومن هذه الأداءات: الانتباه للأشياء الغريبة والمتناقضة، التوقف إزاء العناصر الجديدة وتعميق النظر إليها، التحرك باتجاه المنبهات ذات الخصائص الجديدة والغريبة وتغيير نظامها والتتخل في تركيبها، الفحص الدقيق والاختبار للأشياء والموضوعات الغريبة، البحث عن معالجات وخبرات

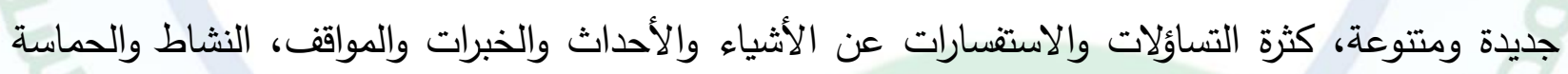
والمغامرة والفضول، الحصول علي درجات عالية من الذكاء، الميل للتحدي والمخاطرة وتقليب الأشياء والظواهر (قطامي، 2000،52).

تتجلي أهمية رياض الأطفال بصلتها الوثيقة بالطفولة المبكرة التي تعد مرحلة مهمة وحاسمة في حياة الإنسان لأنها مرحلة الأساس القوي في بناء الثخصية، وبناء أساسيات المفاهيم والمعارف والخبرات والميول

والاتجاهات (محمد ، 1999،87). 


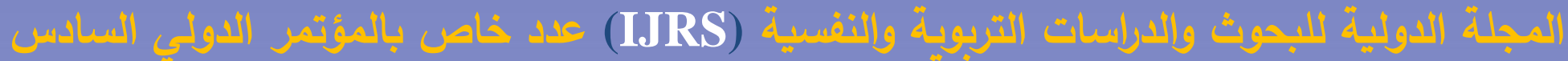

أ.د. راندا مصطفي الديب _ أ. زبنب سميح رمضان إبراهيم ، (برنامج قائم علي محفزات الألعاب الرقمية لتنمية حب الاستطلاع).

والطفل بدخوله مرحلة الروضة ينتقل نقلة أساسية من حيث النمو المعرفي، ذلك أنه بعد أن كان يفكر بجسمه يصبح - الآن - يفكر بعقله وهي نقلة لا تميز - فقط - هذه المرحلة عما قبلها بل تميز النمو المعرفي عند الطفل في المرحلة التالية (حسين ،2015 234).

ويظهر الأطفال منذ بداية حياتهم إشارات علي حبهم للاستطلاع من خلال النظر للآخرين، وتتطور هذه السلوكيات مع تقدهم في العمر حيث يكثرون من الأسئلة التي يطرحوها علي الكبار والتي يعتبرها البعض محرجه لهم، وعند دخولهم المدرسة يبادر الأطفال العاديون بطرح أسئلة متعددة علي المعلمة، كإشارات منهم علي حبهم للاستطلاع واكتشاف الغموض، لذا علي المربين استغلال هذه الفضيلة وإدخالها في طرق التعليم والتعلم التي يستخدمونها وذلك من أجل تحقيق الأهداف التعليمية الخاصة والعامة(غباري، 22،2008).

سادسًا : مبادئ استثارة وتطوير دافع حب الاستطلاع المعرفي لأطفال الروضة: • عدم تجنب الأسئلة : يجب علي معلمة الروضة والأبوين مكافأة الأسئلة الموجهة من قبل الطفل بدلًا من تجنبها. السماح بتوجيه الأسئلة المفتوحة وتجنب الأسئلة التي تحمل إجابة واحدة (نعم/لا): لأن الأسئلة المفتوحة مهمة لأنها تقلل من كمية ونوعية الأسئلة المحتملة وتعمل علي توسيع خيال الطفل وطلاقته في محاولة الإجابة عن الأسئلة وتزيد من رغبته في التعلم. • عدم الإجابة علي الأسئلة المهمة: عادة ما تحتضن أفكارًا قيمة اذا ما أتيح لنا المجال لعدم الإجابة على السؤال بعد طرحه مباشرة، وإذا ما ترك السؤال المهم بدون حل فإنه يثير فضول السائل، وهكذا يمكن زيادة دافع الاستطلاع المعرفي لدى الطفل، لذا ينبغي علينا أن نترك بعض الأسئلة بدون إجابات وذلك لفترة من الزمن، ويجب أن نتظاهر بعدم المعرفة لفترة حتي نتيح مجالًا لتتمية الفضول حتي اذا كنا نعرف الإجابة (الشامي،2012 ،56). 


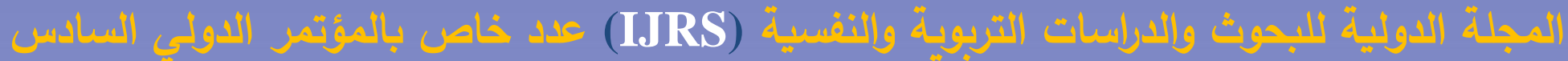

أ.د. راندا مصطفي الديب _ أ. زينب سميح رمضان إبراهيم ، (برنامج قائم علي محفزات الألعاب الرقمية لتنمية حب الاستطلاع).

• إظهار عدم الاكتمال في الناحية المعرفية الحالية: يجب إظهار معرفة غير كاملة؛ فنحن لا نعرف كل شيء عن الطبيعة، وحتي عن أنفسنا، لذا يجب دائمًا إظهار أن هنالك جوانب لم تكتشف بعد، وهذا سيتيح المجال للاستفسار والبحث وتنمية الميول لخلق معرفة أخري. • إظهار الاتجاهات التطورية في المعرفة الإنسانية: تعد رؤيتنا للعالم قاصرة لذلك، فإن بإمكان الأطفال أن يفكروا بالتطورات المستقبلية، وعلي المعلمة والوالدين توجيه الاتجاهات التطورية لديهم في ما يخص

\section{العلوم والتكنولوجيا (الكندري، 2014، 42).}

وتري الباحثتان أنه يجب علي الكبار أن لا ينزعجوا ويملوا من كثرة تساؤلات الطفل بل يجب تشجيعه على أن يسأل ويصبح من الضروري أن يحصل على إجابات صادقة وصحيحة عن تساؤلاته، وأن تكون هذه الإجابات مع صدقها مناسبة لمرحلة نموه العقلي، وأن تستثير هذه الاستجابات فضوله المعرفي إلى مزيد من الأسئلة ومن الاستفسارات، وأن تزيد رغبته في اكتشاف ما حوله ومعرفته الكثير عنه.

$$
\text { إجراءات البحث: تمثلت الإجراءات في الآتي: }
$$

منهج البحث: اعتمد البحث الحالي علي المنهج الوصفي التحليلي، كما اعتمد علي المنهج شبه التجريبي وذلك لمعرفة أثر المتغير المستقل وهو (محفزات الألعاب الرقمية) على المتغير التابع (حب الاستطلاع المعرفي) لأطفال الروضة. أدوات البحث ومواده: تم إعداد أدوات البحث ومواده التالية: 1. إعداد مقياس حب الاستطلاع المعرفي (ملحق 2).

2. إعداد برنامج قائم على محفزات الألعاب الرقمية لتنمية حب الاستطلاع المعرفي لأطفال الروضة (ملحق 3)

وتم عرض أدوات البحث ومواده علي مجموعة من المحكمين وعددهم (12) محكمًا من المتخصصين في مجال رياض الأطفال ومجال تكنولوجيا التعليم ومناهج وطرق تدريس الرياضيات (ملحق 1) 


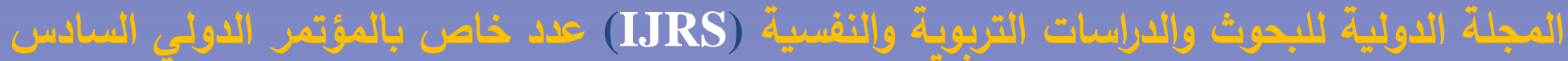

أ.د. راندا مصطفي الديب ـ أ. زينب سميح رمضان إبراهيم ، (برنامج قائم علي محفزات الألعاب الرقمية لتنمية حب الاستطلاع).

\section{نتائج البحث ومناقثة الفروض. \\ أولاًا: مقياس حب الاستطلاع المعرفي.}

1- تحديد الهاف من المقياس: هو قياس حب الاستطلاع المعرفي لاى أطفال الروضة.

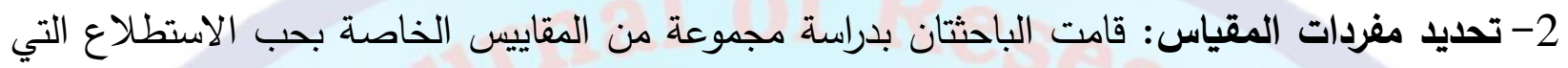

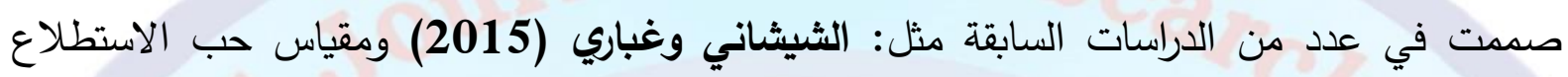

المعرفي - أيضًا- من تصميم وسيط بيني وماكان (Penney,R.y, McCann,B., 1964)

وترجمة شاكر عبد الحميد، وبناء على ما تقدم تكون المقياس من المحاور التانئ التالية:

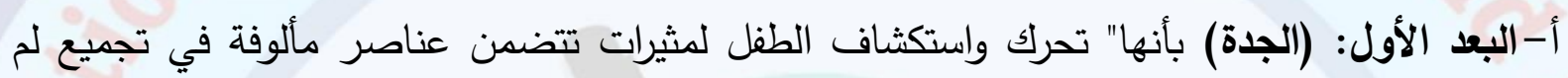

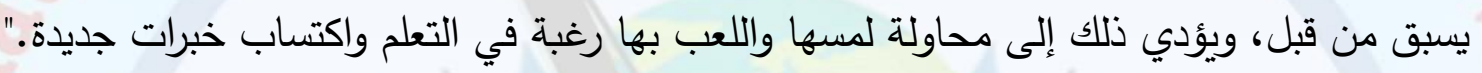

ب- البعد الثاني:(التعقيد) بأنه" مثابرة الطفل في استكثاف المثيرات التي تتصف بكان بكونها محيرة وتشكل

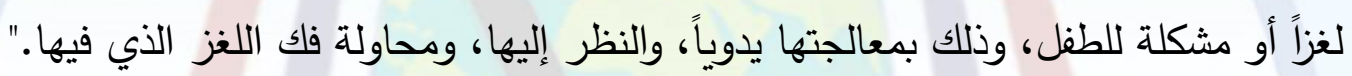

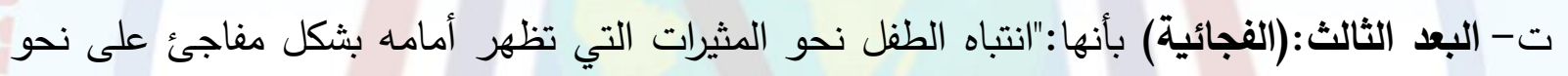

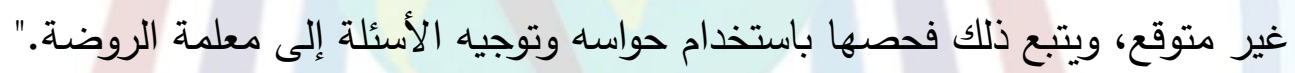

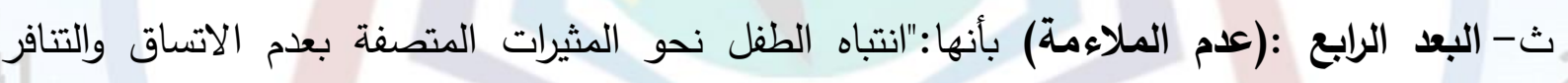

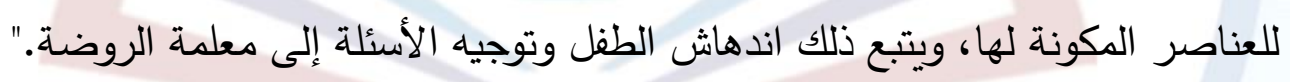

3- صياغة بنود المقياس: استعرضت الباحثان في هذه المرحلة نتائج المرحلة السابقة؛ فقد تم النظر في

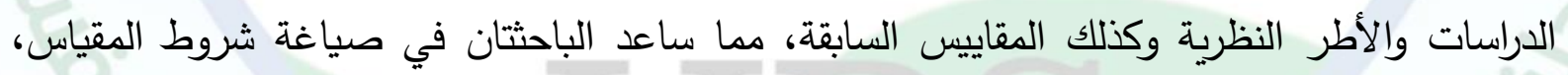

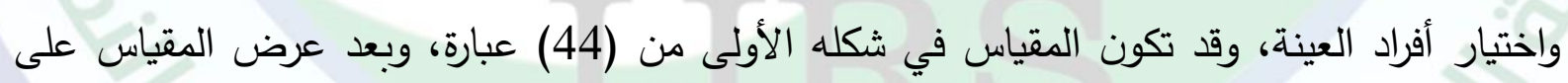

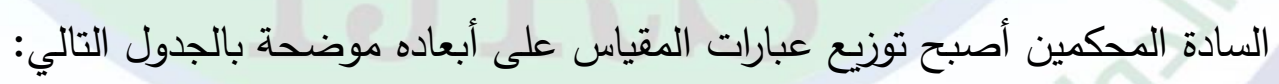




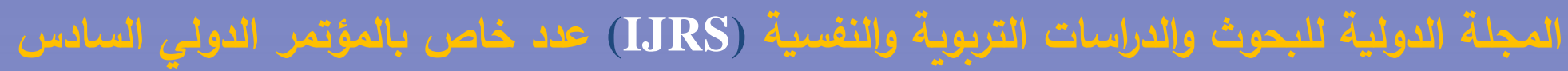
أ.د. راندا مصطفي الديب _ أ. زبنب سميح رمضان إبراهيم ، (برنامج قائم علي محفزات الألعاب الرقمية لتنمية حب الاستطلاع). جدول (2) عبارات مقياس الاتجاه نحو التفاعل موزعة على الأبعاد.

\begin{tabular}{|c|c|c|}
\hline النسبة المئوية 0\% & عدد العبار ات & أبعاد المقياس \\
\hline 27,5 & 11 & الجدة. \\
\hline 25 & 10 & التعقبد. \\
\hline 25 & 10 & الفجائية. \\
\hline 22,5 & 9 & عدم الملاعمة. \\
\hline$\% 100$ & 40 & المجموع \\
\hline
\end{tabular}

4-تحديد بدائل الاستجابة ودرجة المقياس: قد تم الاستعانة بأسلوب الاختيار من ثلاث بدائل بما يتناسب مع (متوفرة بدرجة كبيرة درجة 3، ومتوسطة درجة 2، وغير متوفرة درجة 1، وذلك بالنسبة للعبارات الموجبة بينما العبارات السالبة فيعكس التصحيح ويبدأ بالعكس، أما في حين إغفال الإجابة على واحد أو اثنين من العبارات فقد تم تحديد الدرجة (r) ليتناسب معها، بينما في حالة ترك ثلاثة عبارات فأكثر يتم استبعاد ورقة الطفل تماماً، وبذلك تعتبر القيمة العظمى للمقياس (120) درجة وأقل درجة هي (40)

5- ضبط المقياس وقياس الصدق والثبات.

أ- صدق المحكمين: قامت الباحثتان بعرض المقياس في صورته الأولة على عدد من المحكمين المتخصصين للتعرف على آرائهم حول المقياس من حيث وضوح تعليماته، والأبعاد والصياغة اللغوية، وقد قامت الباحثتان بتعديل كافة العبارات التي اتفق عليها المحكمين بتعديلها أو بحذفها، وقد كانت نسبة اتفاق المحكمين على (95\%) وهي نسبة اتفاق عالية مما يطمئن الباحثتان لتطبيق المقياس على عينة البحث الاستطلاعية. ب-صدق الاتساق الداخلي: وقد قامت الباحثتان بحساب معامل ارتباط بيرسون عن طريق التطبيق وإعادة التطبيق بفاصل زمني قدر أسبوع على العينة الاستطلاعية، وقد تراوحت قيم ارتباط العبارات على أبعاده والدرجة الكلية كما يوضحها الجدول التالي: 


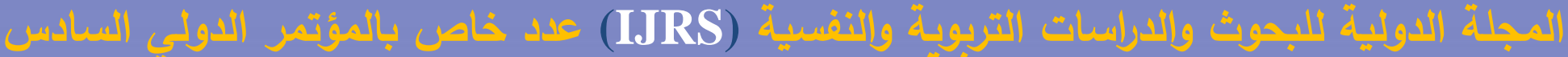
أ.د. راندا مصطفي الديب _ أ. زينب سميح رمضان إبراهيم ، (برنامج قائم علي محفزات الألعاب الرقمية لتنمية حب الاستطلاع).

جدول (3) قيم معامل ارتباط بيرسون على عبارات مقياس حب الاستطلاع المعرفي موزعة على الأبعاد والارجة الكلية للمقياس.

\begin{tabular}{|c|c|c|}
\hline مستوى الدلالة & قيمة الارتباط & أبعاد المقياس \\
\hline$* * 0.01$ & 0.846 & الجدة. \\
\hline$* * 001$ & 0,833 & التعقيد. \\
\hline$* * 0,01$ & 0,758 & الفجائية. \\
\hline$* * 0,01$ & 0,879 & عدم الملاعمة. \\
\hline$* * 0,01$ & 0,851 & المجموع \\
\hline
\end{tabular}

ت-الصدق التمييزي (صدق المقارنة الطرفية): ويقوم على مقارنة متوسطات المجموعات التي حصلت على درجه أعلى وكذلك الدرجة الأقل ثم حساب دلالة الفروق بين هذه المتوسطات، وقد كانت النسبة دالة إحصائيًا عند مستوى (0,05) وذلك يدل على أن المقياس قد حقق قدرًا مطمئنًا لصدق الاختبار •

ث-حساب ثبات المقاييس: تم حساب ثبات المقياس عن طريقة معادلة الفا كرونباخ حيث بلغ (0,783) للمقياس ككل، مما يثير إلى أن المقياس صالحًا للاستخدام العلمي والنفسي ويطمئن الباحثتان للتطبيق على العينة الأساسية وأصبح المقياس في صورة النهائية ملحق(2).

6-التجربة الاستطلاعية للبحث وتكافؤ المجموعات في التطبيق القبلي. قامت الباحثتان بتطبيق التجربة الاستطلاعية للبحث على عينة من نفس الفئة العمرية للأطفال وعددها (10) أطفال، وهم من غير المشتركين في التجربة الأساسية للبحث، والهـف من التجربة الاستطلاعية: هو التعرف على أهم الصعوبات التي قد تواجه الباحثتان أثناء إجراء تجربة البحث، وذلك لتلافيها، أو معالجتها، وقد عملت الباحثتان على تلافي هذه الصعوبات أثثاء القيام بالتجربة الأساسية، والتأكد من صلاحية تطبيق محفزات الألعاب الرقمية لأطفال الروضة، وتقدير مدى ثبات أدوات البحث، وصلاحيتها للتطبيق وكذلك

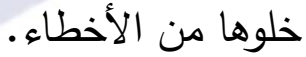
ثانيًا: النتائج الخاصة بمقياس حب الاستطلاع المعرفي لأطفال الروضة: 


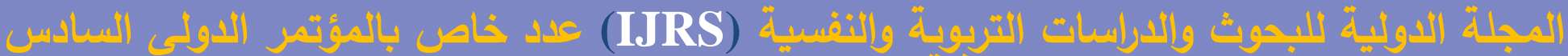

أ.د. راندا مصطفي الديب _ أ. زينب سميح رمضان إبراهيم ، (برنامج قائم علي محفزات الألعاب الرقمية لتنمية حب الاستطلاع).

عرض نتائج البحث المتعلقـة بالكسب العـام في مقيـاس حب الاسـتطلاع المعرفي لأطفـال الروضة:

يوجد فرق دال إحصائياً بين متوسطي درجات أطفال المجموعات التجريبية الثلاثة (الأنثطة التعليمية

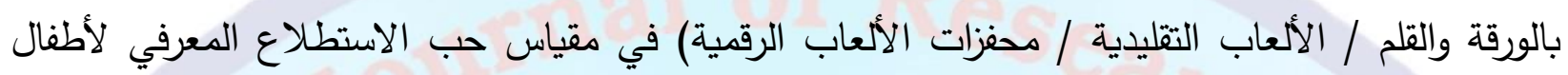

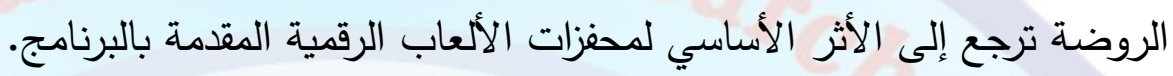

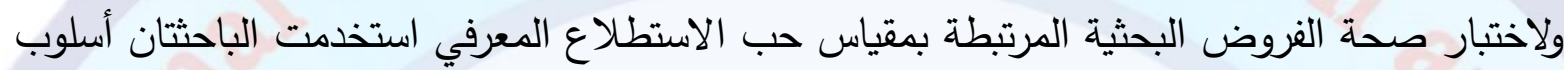

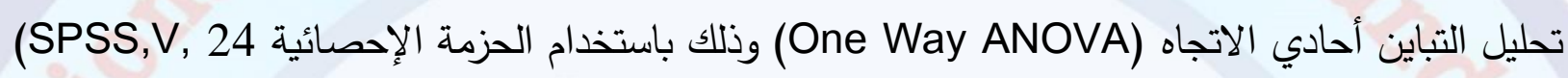
(وفيما يلي عرض للمتوسطات والانحرافات المعيارية لمقياس حب الاستطلاع المعرفي في التطبيق البعدي، وقد تم تطبيق الإحصاء الوصفي للمجموعات الثلاثة في الاختبار، والجدول التالي يوضح المتوسطات والاتحرافات المعيارية للتطبيق البعدي:

جدول (4) حساب المتوسطات والانحرافات المعيارية (مقياس حب الاستطلاع).

\begin{tabular}{|c|c|c|c|c|}
\hline الالنحر اف & المتوسط & 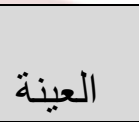 & المجمو عات & الاختبار \\
\hline 2,36 & 57,30 & 20 & الأنشطة التعليمية بالورقة و القلم. & الاستطلاع \\
\hline 1,88 & 87,20 & 20 & الألعاب التقليدية. & \\
\hline 2,98 & 113,45 & 20 & محفز ات الألعاب الرقمية. & \\
\hline 23,26 & 85,98 & 60 & & \\
\hline
\end{tabular}

من الجدول السابق يتضح أن الإحصاء الوصفي للمجوعات الثثاثة في مقياس حب الاستطلاع المعرفي لأطفال الروضة تدل على وجود فورق بين متوسطي درجات الكسب بالنسبة للمتغير المستقل برنامج

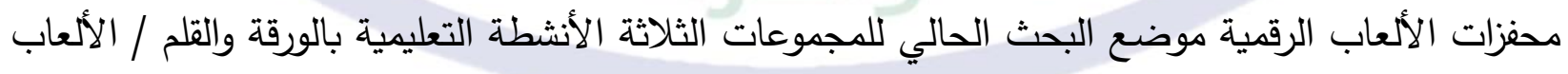
التقليدية/ محفزات الألعاب الرقمية، حيث بلغ متوسط درجة الكسب في مقياس حب الاستطلاع المعرفي 


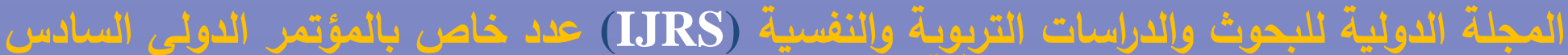

أ.د. راندا مصطفي الديب _ أ. زينب سميح رمضان إبراهيم ، (برنامج قائم علي محفزات الألعاب الرقمية لتنمية حب الاستطلاع).

لأطفال الروضة المجموعة الأولى التي تعلمت بالأنشطة التعليمية بالورقة والقلم حيث إن نسبة المتوسط (57,30) والمجموعة التجريبية الثانية التي تعلمت بالألعاب التقليدية حيث أن نسبة المتوسط بلغت $(87,20)$ والمجموعة الثالثة التي تعلمت بمحفزات الألعاب الرقمية حيث بلغت نسبة المتوسط $(113,45)$.

من الجدول السابق يتضح ووجود فرق دال إحصائياً عند مستوى (05,0) بين متوسطي درجات القياس البعدي في مقياس حب الاستطلاع المعرفي لأطفال الروضة للمجموعات ذات المتوسط الطرفي الأعلى، وهي مجموعة الأطفال الذين تعلموا بمحفزات الألعاب الرقمية حيث يتضح أن هناك تباين في قيمة المتوسط، مما يتطلب الأمر بإجراء تحليلات إحصائية، وذلك باستخدام أسلوب تحليل التباين أحادي الاتجاه من أجل التأكد من وجود فروق دالة من عدمه.

جدول (5) نتائج تحليل التباين أحادي الاتجاه لمجموعات البحث الثلاثة في مقياس حب الاستطلاع.

\begin{tabular}{|c|c|c|c|c|c|c|}
\hline الالالة & "قيمة" & المربعات متوسط & الحرية & المربعاث & مصادر التباين & الاختبار \\
\hline 0,01 & 2628,36 & 15786,32 & 2 & 31572,63 & بين المجمو عات. & \\
\hline 41 & & 6,01 & 57 & 342,35 & داخل المجمو عات. & \\
\hline 28 & & & 59 & 31914,98 & الكل & \\
\hline
\end{tabular}

من الجدول السابق يتضح أن قيمة "ف" تساوي (2628,36) حيث توجد فروق ذات دلالة إحصائية بين متوسطات درجات الأطفال أفراد المجموعات التجريبية الثلاثة في التطبيق البعدي، وبذلك ترفض الباحثتان الفرض الصفرى وقبول الفرض البديل بوجود فرق دال إحصائياً بين متوسطي درجات أطفال المجموعات التجريبية الثلاثة (الأنشطة التعليمية بالورقة والقلم / الألعاب التقليدية/ محفزات الألعاب الرقمية) في مقياس حب الاستطلاع المعرفي لأطفال الروضة، ولمعرفة اتجاه الفروق بين المجموعات التجربية الثلاثة تبعاً لمقياس حب الاستطلاع المعرفي، استخدمت الباحثتان اختبار شفيه للمقارنات البعدية والجدول التالي يوضتح ذلك: 


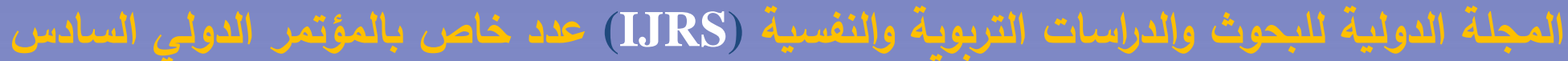

أ.د. راندا مصطفي الديب _ أ. زينب سميح رمضان إبراهيم ، (برنامج قائم علي محفزات الألعاب الرقمية لتنمية حب الاستطلاع).

جدول (6) نتائج اختبار شفيه للمقارنات البعدية في مقياس حب الاستطلاع.

\begin{tabular}{|c|c|c|c|c|}
\hline مستوي الدلالة & اتجاه الفروق & بين المجموعات & المجموعات & المتغير \\
\hline 0,000 & ${ }^{*} 29,90000$ & التجريبية الثانية. & التجرييية الأولى. & \\
\hline 0,000 & ${ }^{*} 56,15000$ & التجرييية الثالثة. & & \\
\hline 0,000 & ${ }^{*} 29,90000$ & التجريبية الأولى & التجريبية الثانية. & \\
\hline 0,000 & ${ }^{*} 26,25000$ & التجريبية الثالثة. & & \\
\hline 0,000 & *56,15000 & التجريبية الأولى. & التجريبية الثالثة. & \\
\hline 0,000 & ${ }^{*} 26,25000$ & التجريبية الثانية. & & \\
\hline
\end{tabular}

باستقراء الجدول وجود فروق دالة إحصائياً عند مستوى 0,01؛ مما يدل على وجود فروق ذات دلالة إحصائية بين متوسطات درجات الأطفال للمجموعات الثلاثة حيث إن اتجاه الفروق في المتوسطات وفق اختبار شفيه كانت لصالح المجموعة التجريبية الثالثة (التي تعلمت بمحفزات الألعاب الرقمية).

ثم كانت لصالح المجموعة التجريبية الثانية (التي تعلمت بالألعاب التقليدية، ثم كانت المجموعة الأولى التي تعلمت بالأنشطة التعليمية بالورقة والقلم) وترجع الباحثتان النتائج الخاصة بمقياس حب الاستطلاع المعرفي لصالح المجموعة الثالثة محفزات الألعاب الرقمية.

وتتفق نتائج البحث الحالي مع ما أكدته دراسة (Marko Urh, et al, 2015) أن استخدام محفزات الألعاب الرقمية له تأثير إيجابي علي عملية التعلم من خلال زيادة الرضا والتحفيز والمشاركة، ونتائج دراسة (Losup,Alexandru;Epema,Dick, 2014) المتعمين وزيادة مشاركتهم في الأنشطة غير العادية والمهام الصعبة بالتدري بتقنية تستخدم عناصر الألعاب الاجتماعية، و - أيضاً- نتائج دراسة (Goodwin,C.J, 2008) أكدت علي أن التكنولوجيا الرقمية يمكن أن توفر فرص مهمة للأطفال الصغار بحيث ينخرطوا في الأفكار الرياضية التي تعرض الاض عليهم،وترجع الباحثتان ما تقدم إلى: 


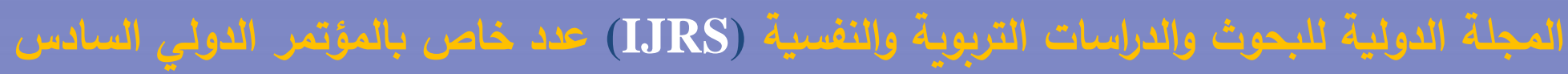

أ.د. راندا مصطفي الديب _ أ. زينب سميح رمضان إبراهيم ، (برنامج قائم علي محفزات الألعاب الرقمية لتنمية حب الاستطلاع).

1. التنوع في الأشكال البصرية في محفزات الألعاب الرقمية التي حفزت الأطفال على تحقيق الأهداف وساعدتهم على التغلب على الارتباطات السلبية التي قد تكون لديهم مع النظام والمهام التي يتطلب منهم إكمالها.

2. أن المكافآت والثارات المستخدمة في محفزات الألعاب الرقمية كانت محركًا للتقدم للطفل، وذات مغزى أكبر، فكلما زادت صعوبة محاولتهح الحصول عليها، كانت زيادة في الرغبة وحب الاستطلاع المعرفي بشكل أكثر .

3. الاعتماد علي محفزات الألعاب الرقمية حرك الإبداع الداخلي للأطفال مما جعلهم أكثر استعدادًا للعب. 4. الاعتماد على تقديم أنشطة متتوعة في محفزات الألعاب الرقمية فعندما لا ينجح الطفل في اللعب وفقًا للقواعد المطلوبة، حاول إيجاد طريقة للتغلب عليها، مما ساعد على زيادة حب الاستطلاع المعرفي. 5. إن مفتاح استخدام محفزات الألعاب الرقمية في التصميم عمل على زيادة المحركات الفسيولوجية الصحيحة مما زاد في شعور الأطفال بحب الاستطلاع المعرفي داخل التطبيق المستخدم. 6. الاعتماد على تقديم التأثير التحفيزي في تصميم محفزات الألعاب الرقمية الأمر الذي ساعد في تطوير وانجاز مهام وأنشطة العمل مما ساعد على زيادة الفضول وحب الاستطلاع المعرفي عند أطفال الروضة. 


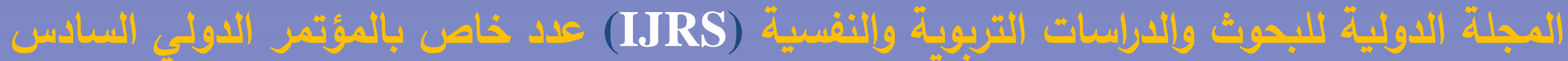

أ.د. راندا مصطفي الديب _ أ. زبنب سميح رمضان إبراهيم ، (برنامج قائم علي محفزات الألعاب الرقمية لتنمية حب الاستطلاع).

$$
\text { نتائج البحث: وهي كما يلي: }
$$

1. وجود فرق دال إحصائياً بين متوسطي درجات أفراد الهجموعات التجريبية الثلاثة (الأنشطة التعليمية

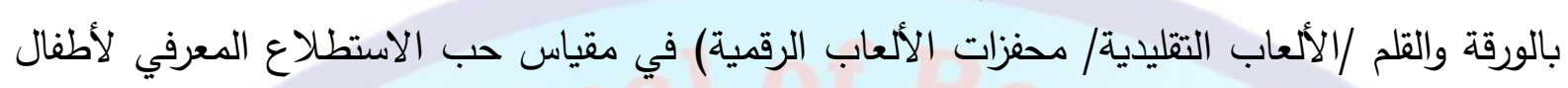

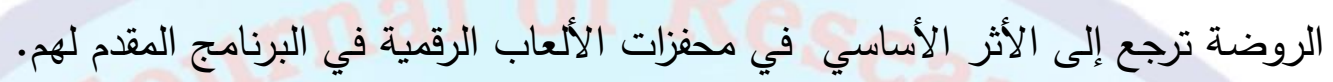
2. وجود أثر لدور محفزات الألعاب الرقمية في تتمية حب الاستطلاع المعرفي لدي أطفال الروضة.

$$
\text { التوصيات: توصلت الدراسة لعدد من التوصيات، وهي كما يلي: }
$$

1. توفير برامج وأنثطة تعليمية إلكترونية في رياض الأطفال تعمل علي تتمية حب الاستطلاع المعرفي لدي الأطفال.

2. ضرورة توعية معلمات الروضة بأهمية حب الاستطلاع المعرفي وأهمية قياسه وتتميته لدى أطفال الروضة.

3. إتاحة الفرص الكافية لطفل الروضة لممارسة أنشطة محفزات الألعاب الرقمية التي تؤدي إلي رفع مستوي

$$
\text { حب الاستطلاع المعرفي لديهم والذي يعد نافذة التعلم الأساسية للإنسان. }
$$

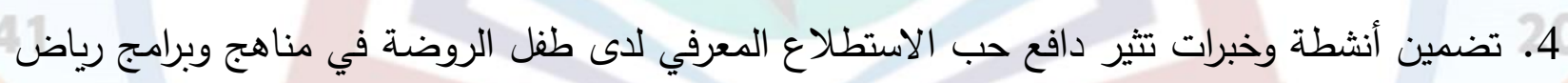
الأطفال.

5. عقد دورات تدريبية لمعلمات الروضة من أجل تتمية كفاءتهن في استخدام محفزات الألعاب الرقمية لدورها في تتمية حب الاستطلاع المعرفي عند الأطفال. البحوث والارراسات المقترحة: وهي كما يلي: 1. برنامج قائم علي محفزات الألعاب الرقمية لتنمية حب الاستطلاع الإدراكي لدي طفل الروضة.

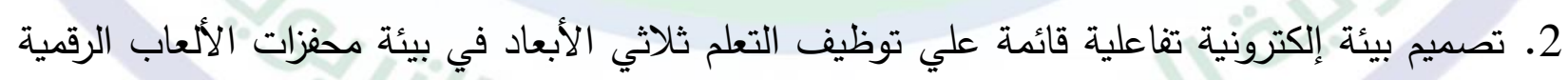

$$
\text { على تتمية حب الاستطلاع لطفل الروضة. }
$$

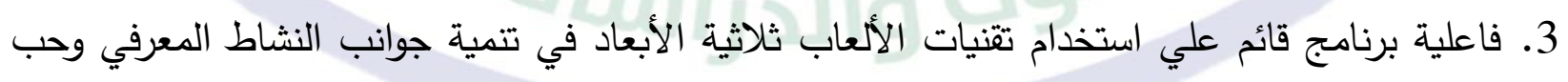
الاستطلاع المعرفي لاى طفل الروضة. 


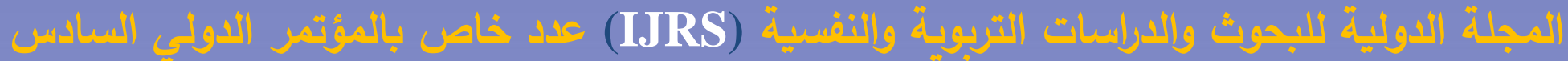

أ.د. راندا مصطفي الديب _ أ. زينب سميح رمضان إبراهيم ، (برنامج قائم علي محفزات الألعاب الرقمية لتنمية حب الاستطلاع).

4. إجراء دراسة تحليلية وصفية للكثف عن أهمية توظيف التقنيات الرقمية ومسابقات محفزات الألعاب للتعليم والتقييم في قاعات النشاط.

\section{المراجح.}

أولاً: المراجع العربية.

• حسن، أحمد (2017): فاعلية محتوي إلكتروني في مادة الحاسوب قائم علي إستراتيجية الألعاب التنافسية الرقمية في تنمية التحصيل وكفاءة التعلم لدي تلاميذ المرحلة المتوسطة بالمملكة العربية السعودية، رسالة ماجستير غير منشورة، كلية الدراسات التربوية، الجامعة المصرية للتعلم الإلكتروني. برلاين (1993): علم النفس المعرفي "الصراع - الاثارة - حب الاستطلاع" ترجمة كريمان بدير، وزارة الثقافة، القاهرة. الملاح، تامر المغاوري، وفهيم، نور الهدي محمد (2016): الألعاب التعليمية الرقمية والتنافيية "رؤينة جديدة عن التلعيب"، دار السحاب، القاهرة. حسن، تسبيح أحمد فتحي (2017): تصميم بيئة تعلم قائمة علي محفزات الألعاب الرقمية لتتمية مهارات حل المشكلات وبعض نواتج التعلم لدي تلاميذ الحلقة الابتدائية، رسالة ماجستير غير منشورة، كلية الدراسات العليا للتربية، جامعة القاهرة. غباري، ثائر أحمد (2008): فاعلية نموذج تدربي مبني علي إثارة حب الاستطلاع في تحصيل مادة العلوم لدي تلامذة الصف الثاني الأساسي في مديرية التربية والتعليم بقصبة إربد، مجلة جامعة الثارقة للعلوم الإنسانية والاجتماعية، مجلد 5. الثامي، جمال الدين، (2012): دافع حب الاستطلاع والأسلوب المعرفي كمنبئات بالخيال الإبداعي لدي المرتفعين والمنخفضين تحصيليًا من تلاميذ المرحلة الإبتدائية، مجلة التربية الخاصة، جامعة المنصورة، جمهورية مصر العربية. القحطاني، خالد (2019): تصميم بيئة تعلم إلكتروني قائمة علي الدمج بين الأنشطة التفاعلية ومحفزات الألعاب الرقمية "Gamification" لتمية بعض المهارات الحياتية لدي أطفال الروضة بمنطقة تبوك، المجلة التربوية الدولية المتخصصة، مجلد(8)، عدد(3)، دار سمات للدراسات والأبحاث. 


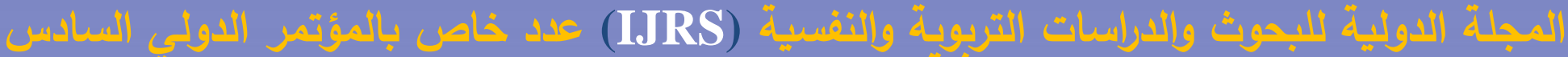

أ.د. راندا مصطفي الديب _ أ. زبنب سميح رمضان إبراهيم ، (برنامج قائم علي محفزات الألعاب الرقمية لتنمية حب الاستطلاع).

خليفة، رحاب (2016): أثر توظيف الرحلات المعرفية عبر الويب لتدريس الاقتصاد المنزلي في مستوي التفكير التأملي وحب الاستطلاع المعرفي لدي تلميذات المرحلة الثانوية، دراسات عربية في التربية وعلم النفس، عدد(77) رابطة التربويين العرب.

شنودة، رضا جرجس، وعبد الكريم، مني عيسي (2020): فاعلية التعليم المدمج القائم علي محفزات الألعاب الرقمية في زيادة التحصيل وتتمية التفكير الإيجابي لدي طلاب شعبة إعداد معلم الحاسب الآلي، مجلة البحث العلمي في التربية، المجلد (8)، عدد( 21)، كلية الآداب للبنات والعلوم والتربية، جامعة عين شمس. الهويدي، زيد (2005): الألعاب التربوية (استراتيجية لتنمية التفكير) دار الكتاب الجامعي، العين. موسي، سعيد عبدالمعز علي (2015): فاعلية القصص التفاعلية الإلكترونية في تنمية حب الاستطلاع والمهارات الاجتماعية لدي أطفال الروضة، مجلة الطفولة والتربية، مجلد (7) عدد (21) كلية رياض الأطفال، جامعة الإسكندرية. عبدالمولي، السيد (2015): أثر برمجية مقترحة قائمة علي الألعاب الإلكترونية في تتمية بعض مهارات الثقافة البصرية واستخدام الحاسوب لدي الأطفال ذوي الإعاقة السمعية،المؤتمر الدولي الرابع للتعلم الإلكتروني والتعليم عن بعد، من 2-5 مارس، جامعة الامام عبد الرحمن بن فيصل، الرياض. محمد، عادل (1999): دراسات سيكولوجية نمو الطفل وطفل الروضة، دار الرشاد، القاهرة. العمري، عائشة بلهيش (2015): الألعاب التعليمية: مميزاتها، أنماطها، مراحل تصميمها، متاح http://learning-otb.com/index.php?option=com علي الرابط التالي الشعراوي، علاء محمود ( 1997) : حب الاستطلاع وعلاقته بالتوافق لدي عينة من تلاميذ الصف الثالث بالحلقة الأولى من التعليم الأساسي، مجلة كلية التربية، عدد (3) جامعة المنصورة. حسين، فداء (2015): أثر برنامج تدريبي مستند الي اللعب التركيبي في تنمية حب الاستطلاع لدي رياض الأطفال، رسالة ماجستير غير منشورة، كلية الدراسات العليا، الجامعة الهاشمية، الأردن. عبدالسلام، كريمان محمد (1998): السلوك الاستكثافي عند الأطفال: دراسة مجموعات عمرية متتابعة في بيئات حضارية مختلفة، رسالة دكتوراه غير منشورة، كلية البنات، جامعة عين شمس. 


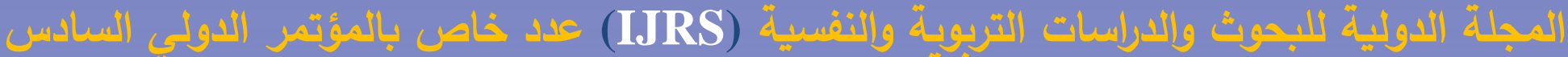

أ.د. راندا مصطفي الديب _ أ. زبنب سميح رمضان إبراهيم ، (برنامج قائم علي محفزات الألعاب الرقمية لتنمية حب الاستطلاع).

القضاة، محمد القضاة (2013): فعالية برنامج تدربي قائم علي استراتيجية لعب الدور في تتمية حب الاستطلاع المعرفي لاي عينة من أطفال الروضة، مجلة رسالة التربية وعلم النفس، عدد(43) الجمعية

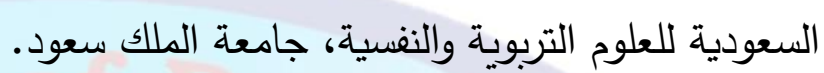

حس، محمود محمد شبيب (1992): مدي فاعلية برنامج تدريبي لحب الاستطلاع في تعلم بعض

المفاهيم العلمية لدي طلاب الصف الأول الثانوي، رسالة دكتوراه غير منشورة، كلية التربية، جامعة قنا. القايد، مصطفي (2015): ما هو التلعيب؟ مقالة، موقع تعليمي جديد، متاح علي الرابط التالي:

http://www.new-edu.comlgamification-education.

السيد، مصطفي عبدالرحمن، وسلطان، صفاء عبدالعزيز (2015): فاعلية نموذج التعلم البنائي في تعديل التصورات الخاطئة نحو مفاهيم الويب الدلالي وتتمية دافع حب الاستطلاع لدي طلاب كلية التربية، مجلة دراسات عربية في التربية وعلم النفس، عدد (68) رابطة التربويين العرب، السعودية. عبدالله، معتز سيد (1993): الدافعية،الطبعة الثالثة، دار غريب للطباعة والنشر والتوزيع، القاهرة. الكندري، مناير محمد علي (2014): تصميم القصة الإكترونية لأطفال ما قبل المدرسة في ضوء معايير تتمية الخيال الإبداعي وأثرها علي تتمية مهارات حب الاستطلاع، رسالة ماجستير غير منشورة، كلية الدراسات العليا، جامعة الخليج العربي، البحرين. نبيل عبدالهادي (2004): حب الاستطلاع وأثره في التعليم ، دار وائل للنشر والتوزيع، القاهرة. بخش، هالة (2008): أثر برنامج قائم علي الوسائط المتعددة في العلوم علي تتمية حب الاستطلاع والابتكارية لدي تلاميذ الصف الأول والمتوسط، المجلة التربوية، جامعة الكويت، مجلد (22) عدد(86). الثيشاني، هناء ذياب جمعه، وغباري ثائر أحمد (2015): الأنماط الوالدية وعلاقتها بدافع حب الاستطلاع المعرفي لدي أطفال الروضة: دراسة ميدانية علي أطفال الروضة في مديرية التربية والتعليم لقصبة الزرقاء، رسالة ماجستير غير منشورة، الجامعة الهاشمية، الأردن. قطامي، يوسف (2000): نمو الطفل المعرفي واللغوي، الأهلية للنشر والتوزيع، عمان، الأردن.

- Amone,M. (2003): Instructional Design Strategies that Foster Curiosity. 


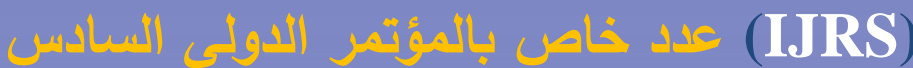

أ.د. راندا مصطفي الديب ـ أ. زينب سميح رمضان إبراهيم ، (برنامج قائم علي محفزات الألعاب الرقمية لتنمية حب الاستطلاع).

- Collin,S.(2000):Multimedia Mad Simples.Jordan Hall, Oxford. UK.

- Deterding,S.,Sicart,M.,Nacke,L.,O’Hara,K.,\&Dixon,D.(2011).Gamification.usi ng game-design elements in non-gaming contexts.In proceedings of $\mathrm{CHI}$ Extended Abstracts.

- Diana G. Oblinger.(2006).Games and learning, Educause Quarterly Magazine, 29, Number (3), pp.5-7.

- Driscoll,M.(2000):Psychology of Learning for Instruction. Needham Heights,MA:Allyn\&Bacon.

- Fisher, Kathleen, Curioser and Curioser (2000): The vartue of wonder. Journal of Education. 182 (2).

- Goodwin,C.J(2008):Ahistory of modern Psychology ( ${ }^{\text {rd }}$ ed.).John Wiley\&Sons Inc.

- Karl.m.Kapp (2012): The gamification of learning and instruction: Game-based methods and strategies for training and education .San Francisco:Pfeiffer.

- Kasvi JJJ(2000).Not Just fun and games - internet games as atraining medium. In:Kymaalainen P,Seppanen L (eds) Cosiga- Learning with computerised simulation games.HUT, Espoo,pp.23-34.

- Losup,Alexandru;Epema,Dick (2014): H.J.\An experience report on using gamification in technical higher education. The45th ACM Technical Symposium on computer Science Education, SIGCSE,14,Atlanta,GA,USAMarch05-08,Association for computing Machinery,Inc,2014.pp.27-32.

- Mark Griffiths,(2002):The Educational benefits of videogames, Education and health,Vol.(20),No.(3)

- Marko Urh, Goran Vukovic, Eva Jereb, Rok Pintar(2015):The model for introduction of gamification into e-learning in higher education, $7^{\text {th }}$ World Conference on Educational Sciences, (WCES- 2015),5-7 February2015, Novotel Athhens Convention Center,Athens, Greece, Procedia - Social and Behavioral Sciences 197(2015)388-397.

- Penney,R.y McCann,B.(1964):The childrens reactive curiosity scale.psychological reports. 15,323-334.

International Journal of Research and Studies (ij rs) It is issued by the Excellence Pioneers Academy The Online ISSח :(2735-5063) - The print ISSח :(2735-5055). 


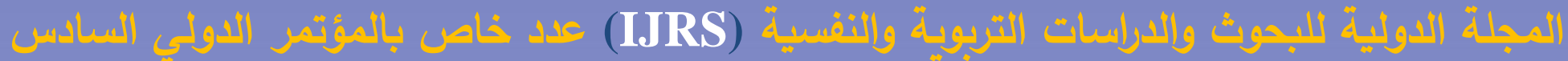
أ.د. راندا مصطفي الديب ـ أ. زينب سميح رمضان إبراهيم ، (برنامج قائم علي محفزات الألعاب الرقمية لتنمية حب الاستطلاع).

- Smith-Robbins, S (2011): This game sucks: How to improve the Gamification of education. EDUCASE review ,46(1), 58-59.

- Zichermann, Gabe\&Cunningham, Christopher (2011)."Introduction" Gamification by Design :Implementing Game Mechanics in Web and Mobile Apps ( $1^{\text {st }}$ ed). Sebastopol,California:O'Reilly Media.P.xiv. ISBN 1449315399.

\section{الملاحق.}

ملحق (1) قائمة بأسماء السادة المحكمين علي أدوات البحث ومواده.

\begin{tabular}{|c|c|}
\hline 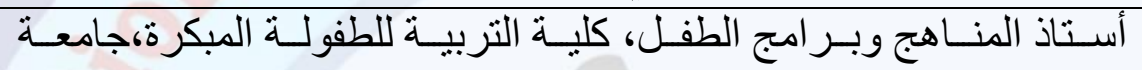 & 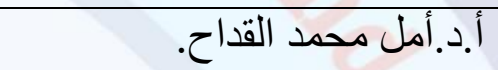 \\
\hline المنصورة. & \\
\hline أستاذ أصول تربية الطفل، كلية التربية للطفولة المبكرة، جامعة القاهرة. & السيد عبدالقادر شريف. \\
\hline أستاذ تكنولوجيا التعليم و عميد كلية التربية النو عية، جامعة طنطا. & حمدي اسماعيل شعبان. \\
\hline أستاذ المناهج وطرق تدريس تكنولوجيا التعليم، كلية التربية،جامعة طنطا. & 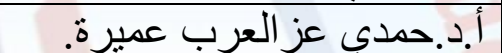 \\
\hline أستاذ تكنولوجيـا التعليم ورئيس قسم التكنولوجيـا، كلية التربيـة النوعيـة، & سناء عبدالعاطي الطباخ. \\
\hline جامعة طنطا. & \\
\hline جامعة كفر الثيخ. أطفل المسـاعد ورئيس قسم رياض الأطفال، كليـة الإ & \\
\hline 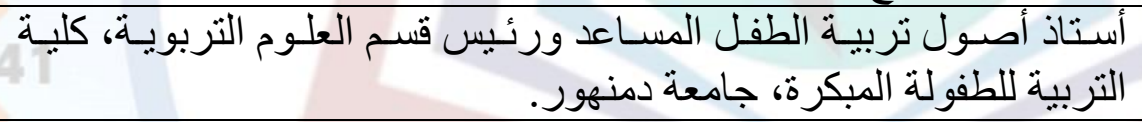 & \\
\hline طنطا. مدرس الرسم والتصوير بقسم التربية الفنية، كلية التربيـة النوعية، جامعـة & 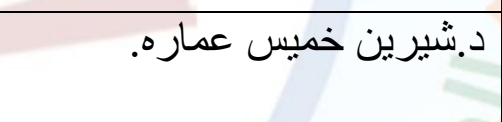 \\
\hline أستاذ ورئيس قسم تكنولوجيا التعليم، كلية التربية،جامعة المنصورة. C & أ.د. عبدالعزيز طلبه عبدالحميد \\
\hline أستاذ المناهج وطرق تدريس الرياضيات، كلية التربية، جامعة كفر الثيخ. & أ.د. عبدالجو اد عبدالجو اد بهوت. \\
\hline أستاذ طرق تدريس ومناهج الرياضيات، كلية التربية، جامعة طنطا. & أ.د.علاء المرسي أبوالر ايات. \\
\hline كلية التربية، جاد & 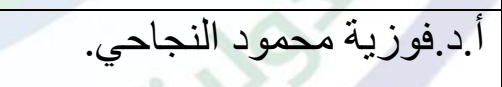 \\
\hline
\end{tabular}


ملحق (2): مقياس تقدير حب الاستطلاع المعرفي لأطفال الروضة من وجهة نظر المعلمة

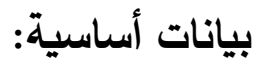

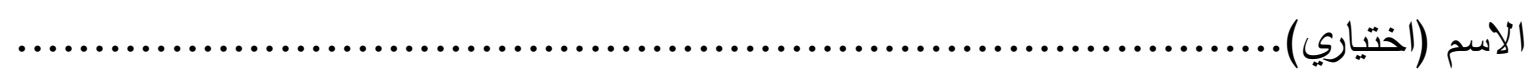

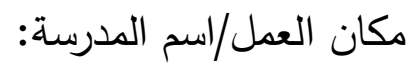

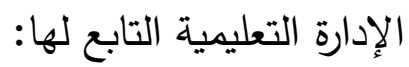

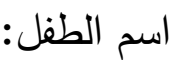

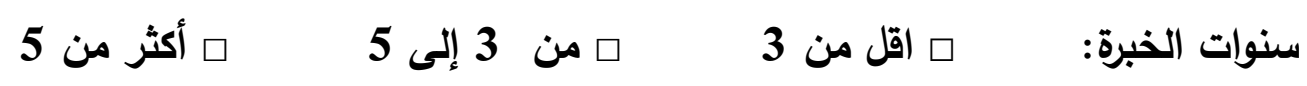

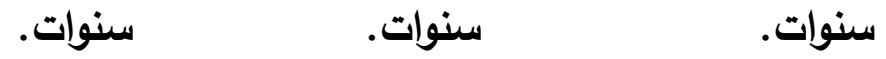

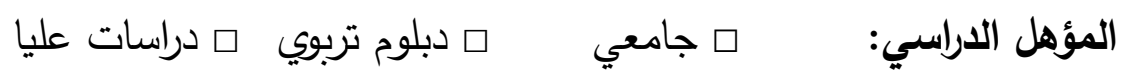

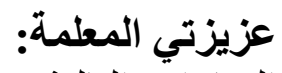

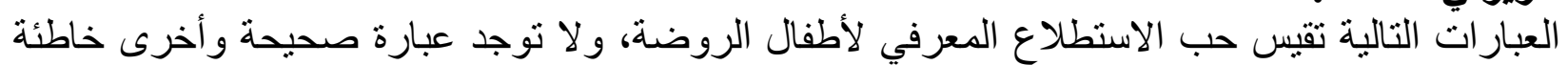

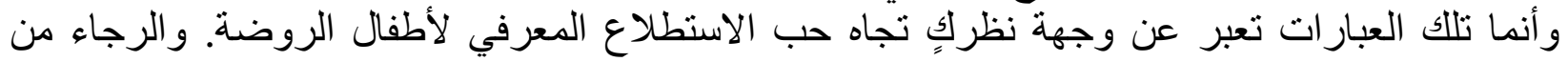
سيادتاكِ القيام بوضع العلامة المناسبة في الخانة التي تعبر عن وجهة نظركٍِ. 


\begin{tabular}{|c|c|c|c|c|}
\hline متلعديل & ت تنتمي & ت تنتمي & العبارات & \\
\hline \multicolumn{5}{|c|}{ 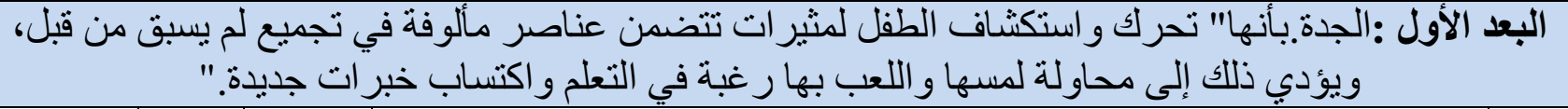 } \\
\hline & & & يتحرك الطفل نحو المثير ات الجديدة. & 1 \\
\hline & & & يستكثف الطفل الألعاب المكونة من خامات جديدة. & 2 \\
\hline & & & يلمس الطفل الأشياء الجديدة في الفصل. & 3 \\
\hline & & & يبحث الطفل عن المثيرات غير العادية. & 4 \\
\hline & & & يحب الطفل اللعب بالألعاب غير المألوفة. & 5 \\
\hline & & & يرغب الطفل في معرفة كل ما هو جديد عليه. & 6 \\
\hline & & & يسأل الطفل عن كيفية عمل سيارة مكونة من الورق المقوي. & 7 \\
\hline & & & يبحث الطفل عن الأشياء الجديدة في الكتب الخاصة بالروضة. & 8 \\
\hline & & & يستخدم الطفل الصلصال في ابتكار أثكال جديدة. & 9 \\
\hline & & & 1 | يبتكر الطفل لعب مختلفة باستخدام خامات البيئة. & 10 \\
\hline & & & 1 | يلفت نظر الطفل كل ما هو جديد. & 11 \\
\hline \multicolumn{5}{|c|}{ 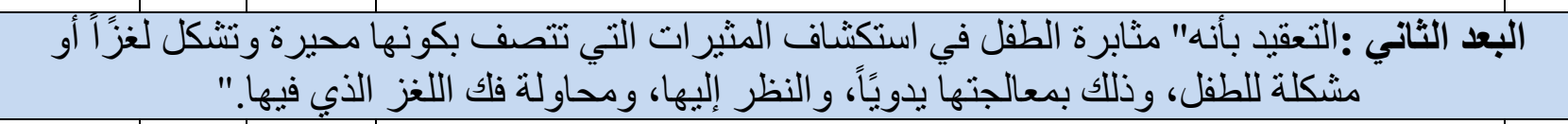 } \\
\hline & & & يثابر الطفل في استكثاف الألعاب التي لا يفهم كيف تعمل. & 1 \\
\hline & & & يميل الطفل إلى اللعب بألعاب الألغاز. & 2 \\
\hline & & & يستمتع الطفل بألعاب المتاهة. & 3 \\
\hline & & & يميل الطفل إلى اللعب بالألعاب التي تشكل لغزاً بالنسبة له. & 4 \\
\hline & & & يقوم الطفل بالمعالجة اليدوية للعب المركبة الغامضة. & 5 \\
\hline & & & لا يستسلم الطفل إذا واجها شيء يصعب عليه فهمه. & 6 \\
\hline & & & يحب الطفل اللعب بألعاب الفك و التركيب. & 7 \\
\hline & & & يسأل الطفل المعلمة عن الأشياء التي يصعب عليه فهمها. & 8 \\
\hline & & & يغضب الطفل إذا عجز عن حل المشكلات التي تو اجهه. & 9 \\
\hline & & & 1 | يبحث الطفل عن إجابة أعمق من تلك التي تقدم له. & 10 \\
\hline
\end{tabular}




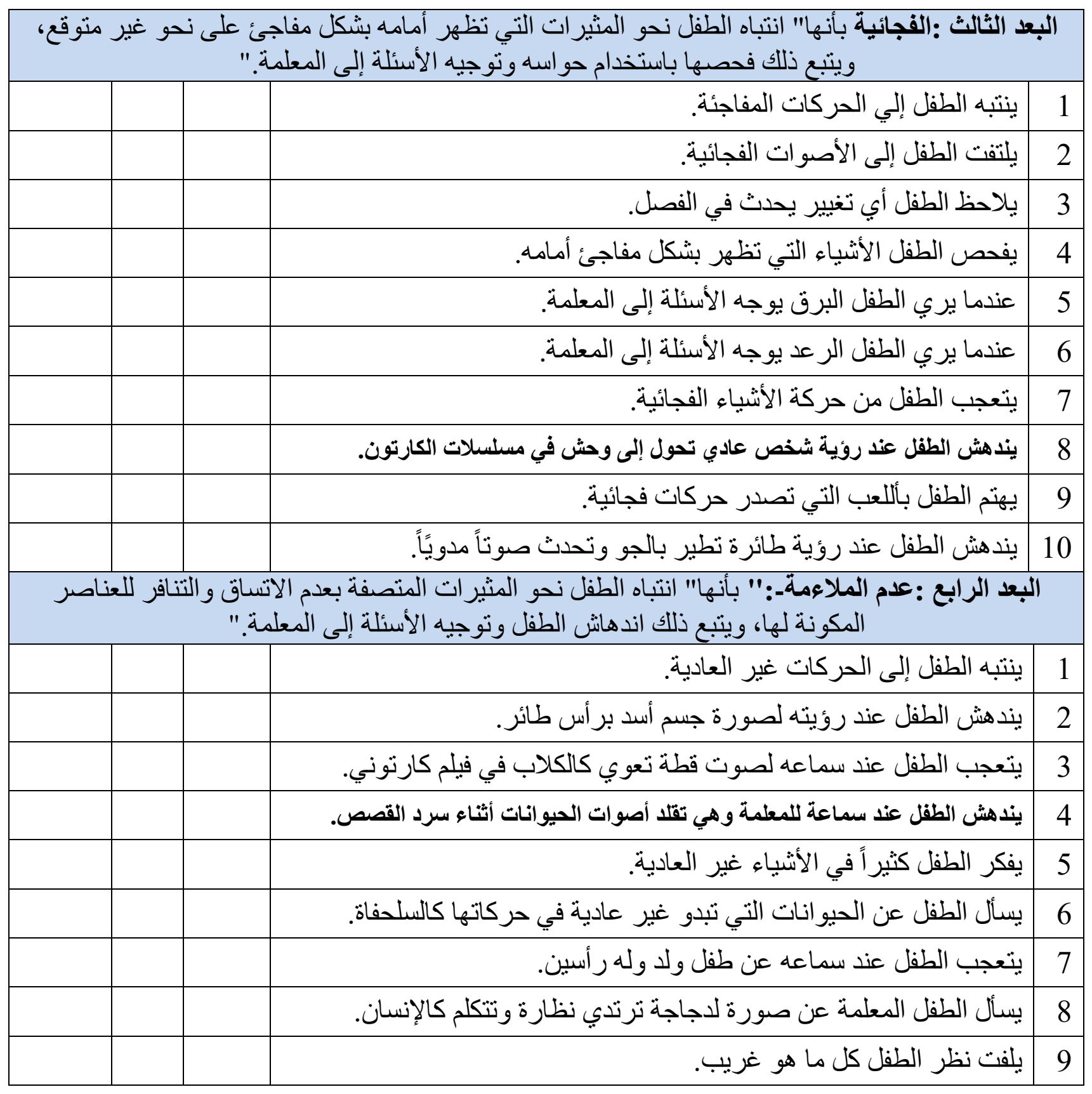




\section{ملحق (3) معايير تصميم.}

برنامج قائم علي محفزات الألعاب الرقمية لتنمية حب الاستطلاع المعرفي لأطفال الروضة (تساؤلات أطفال الروضة الخاصة بحب الاستطلاع المعرفي).
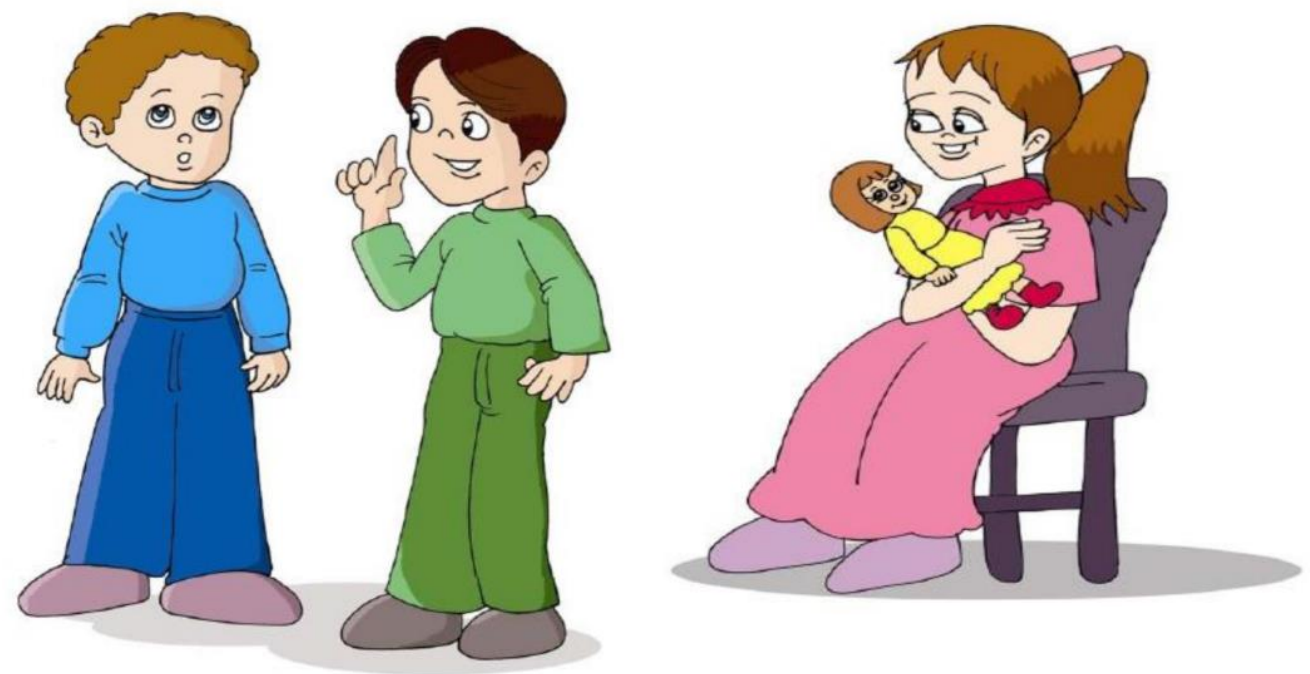

- اسال دوما لماذا شعري ناعم واملس شعر ابن الجيران خشن؟

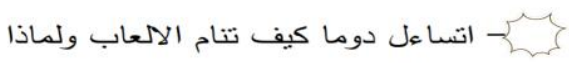

$$
\begin{aligned}
& \text { • لا نتكلم }
\end{aligned}
$$




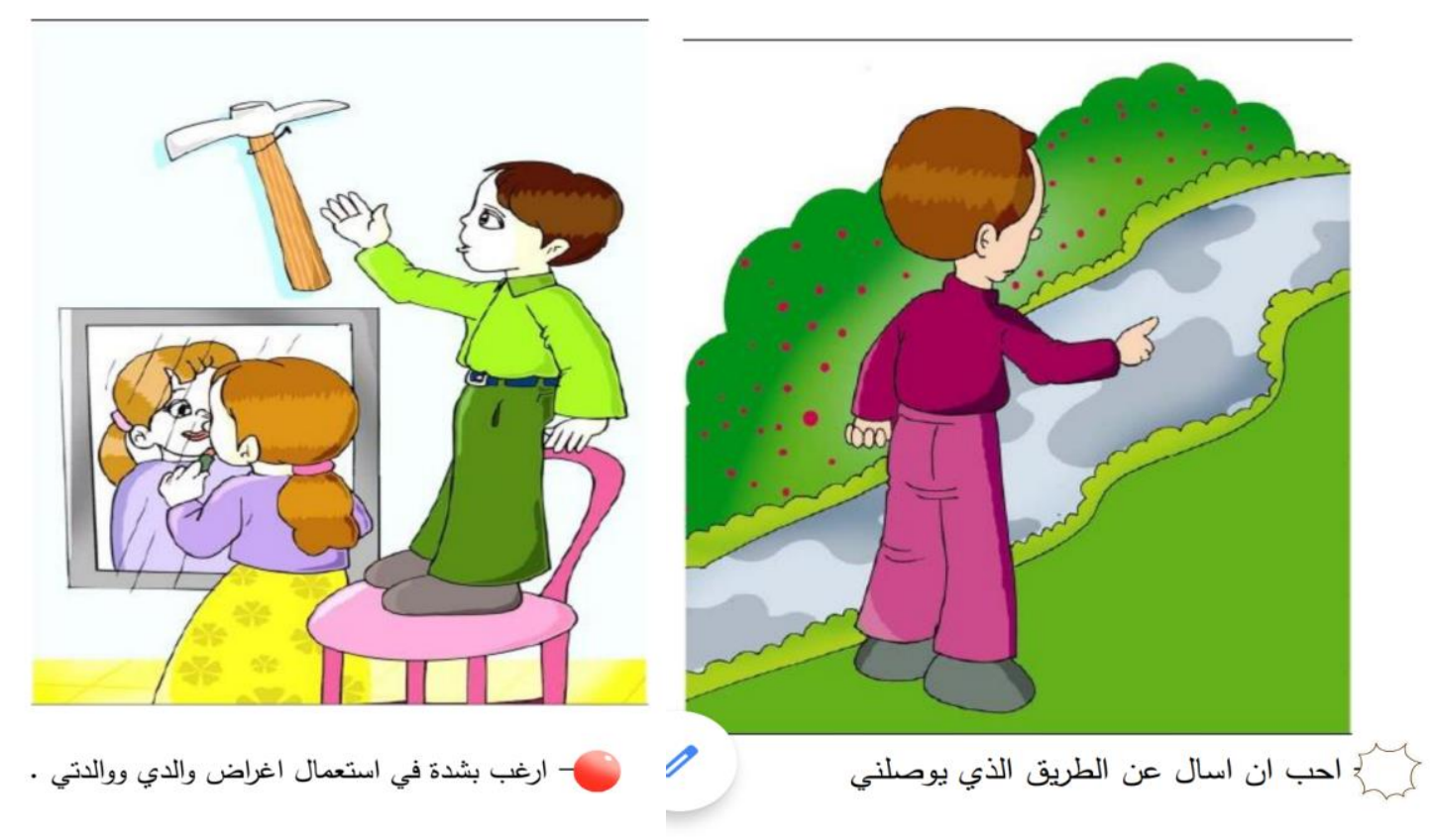




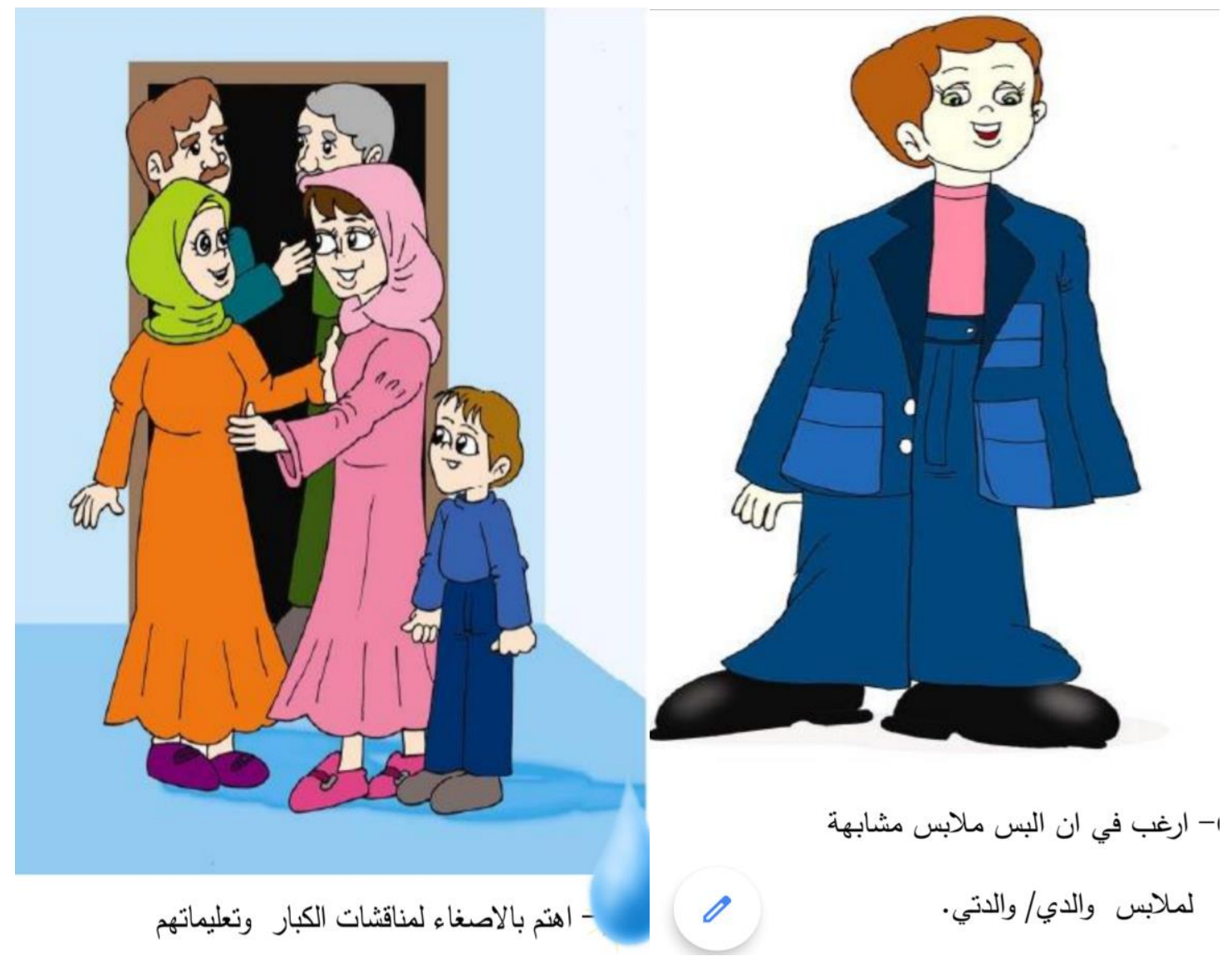



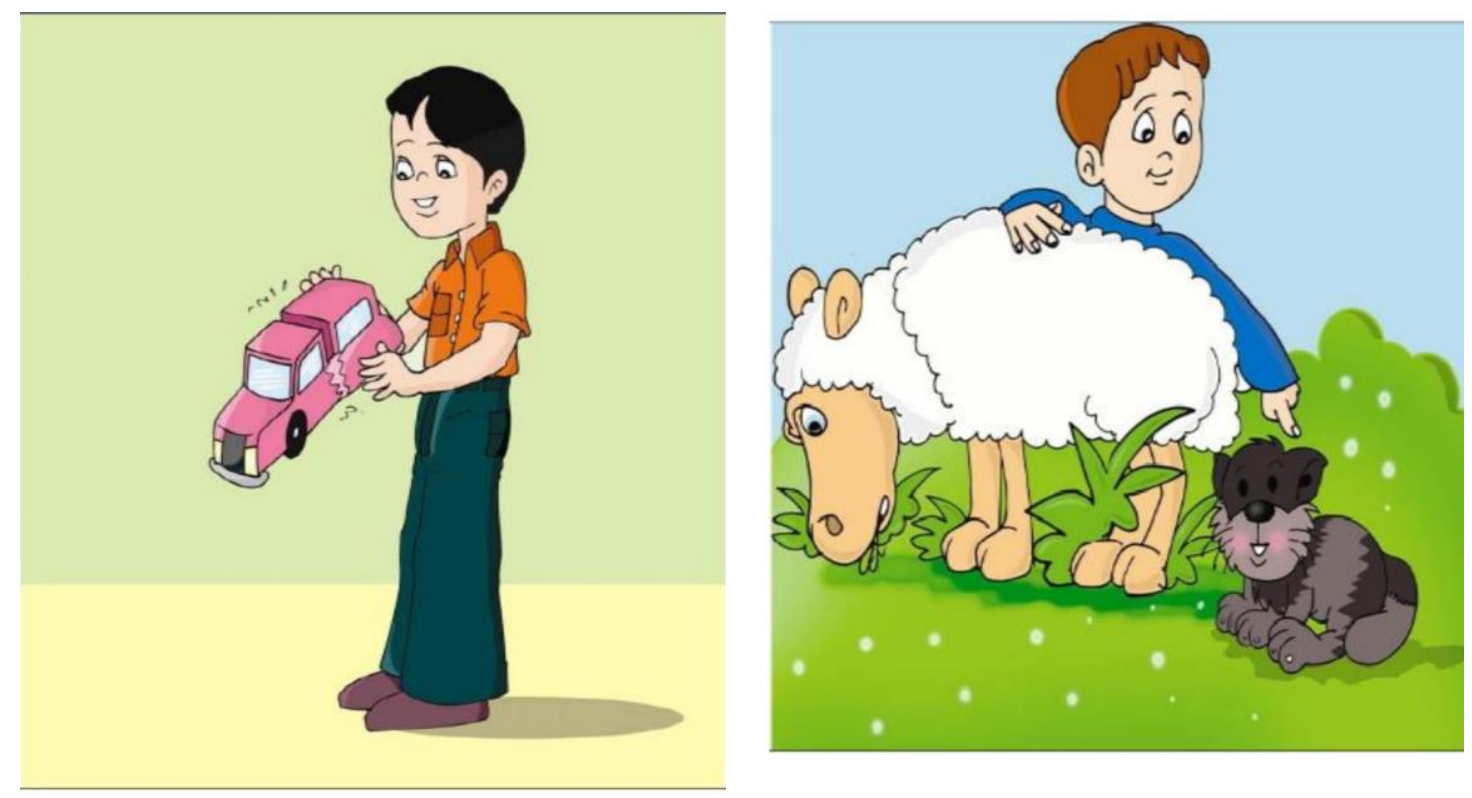

- احب ان اراقب الاغنام والقطط لاعرف كيف تتمو وتتغذى. - م- احب ان العب بالاعاب الجديدة زاهية الالوان . 


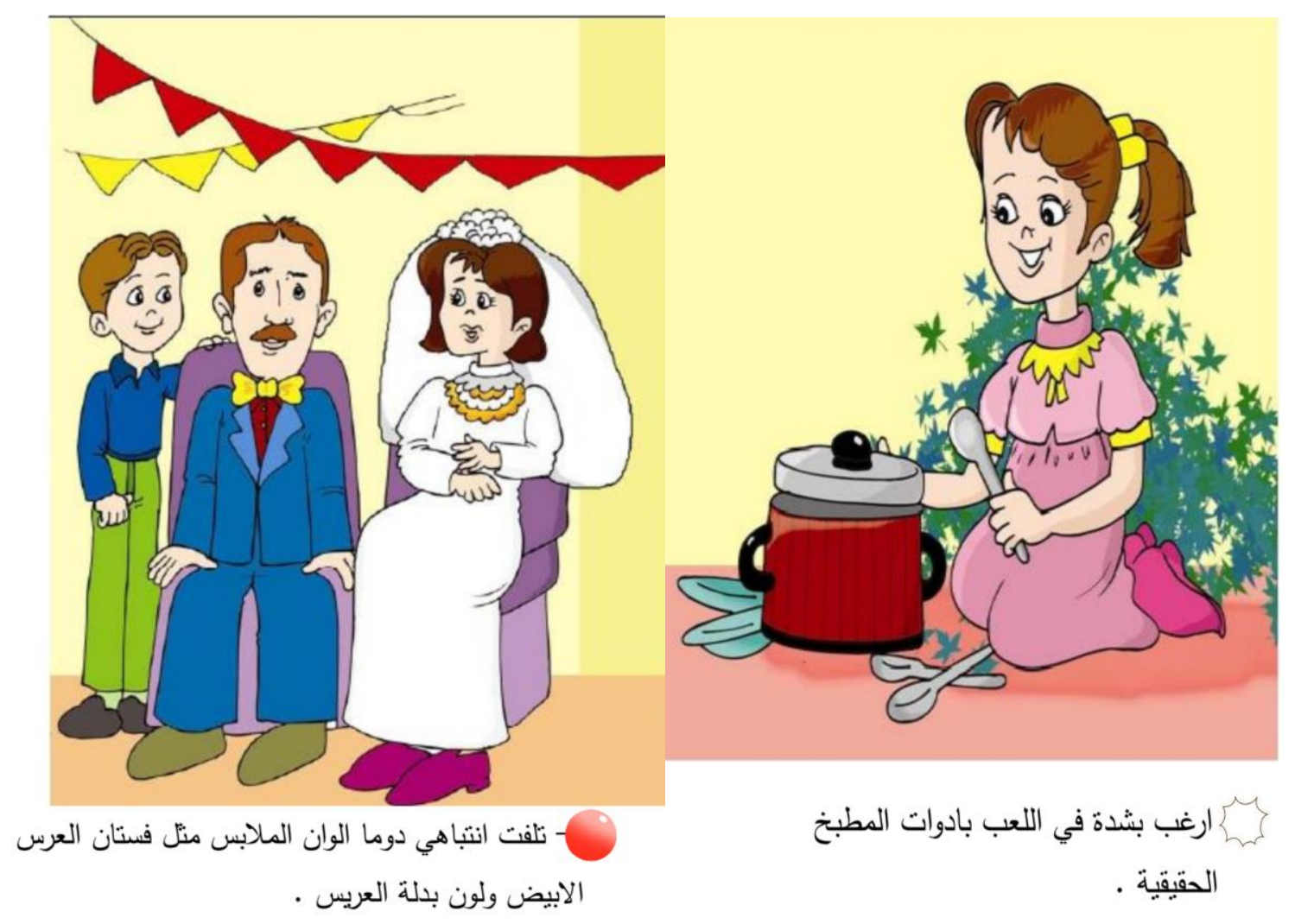



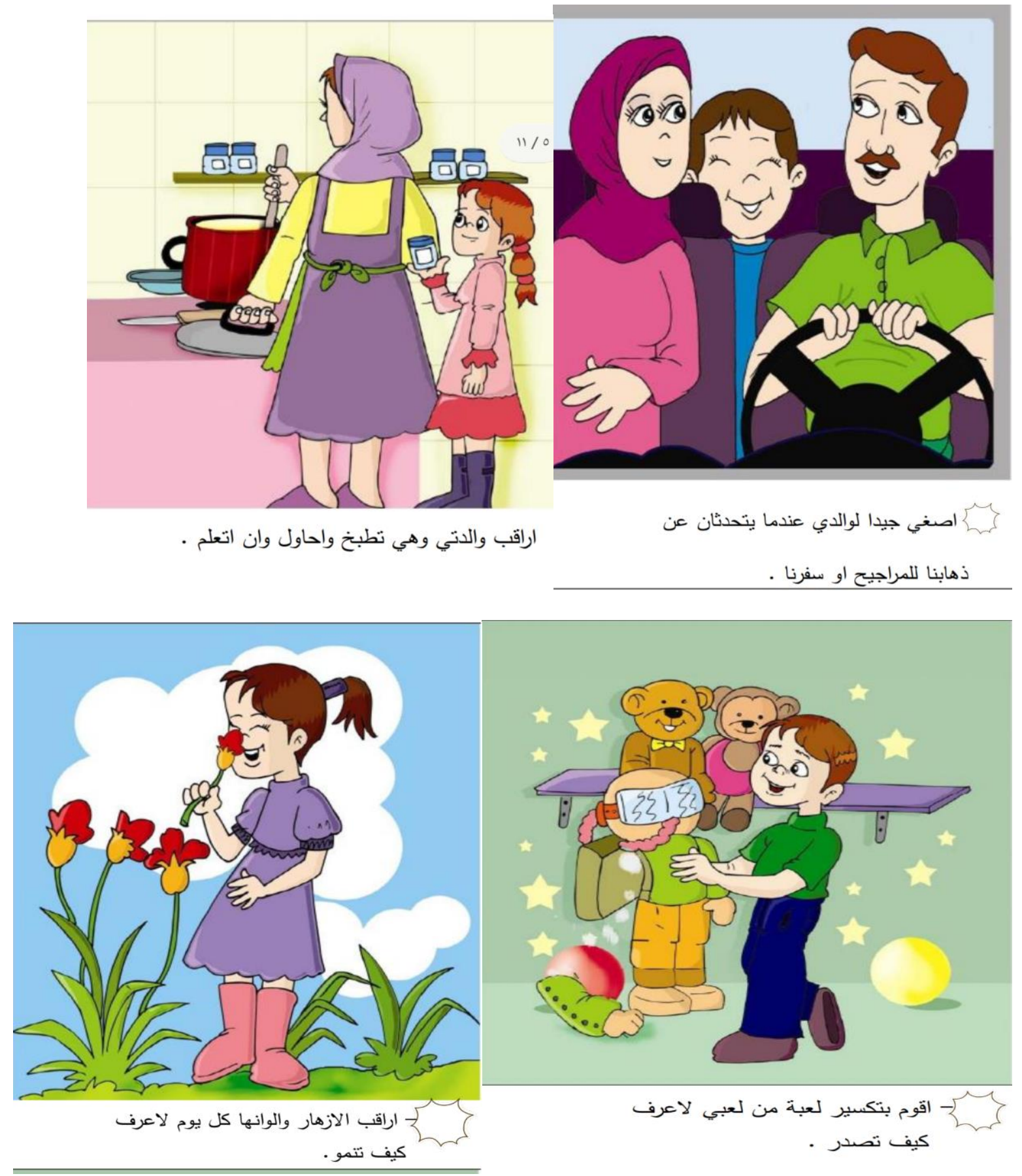

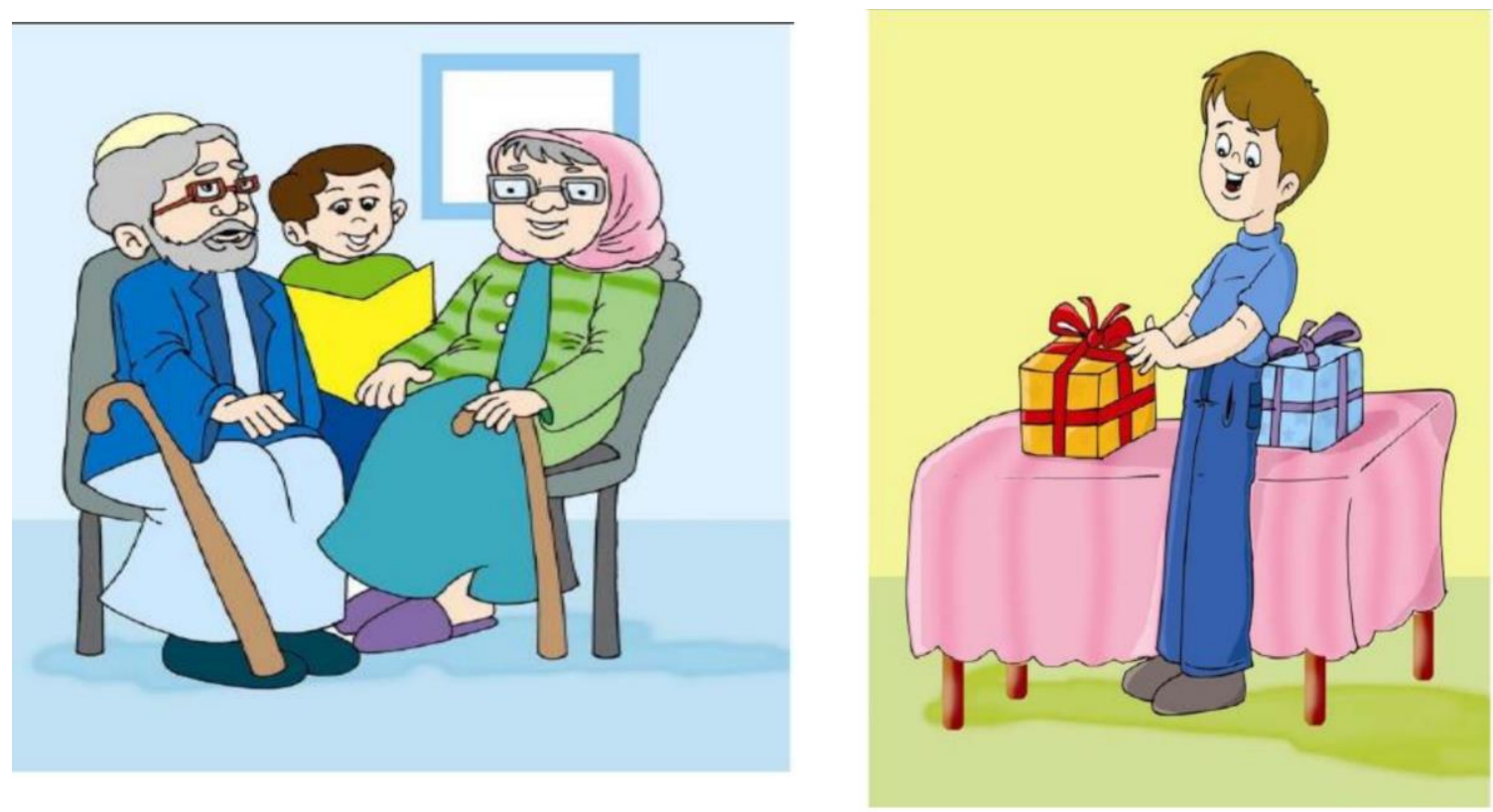

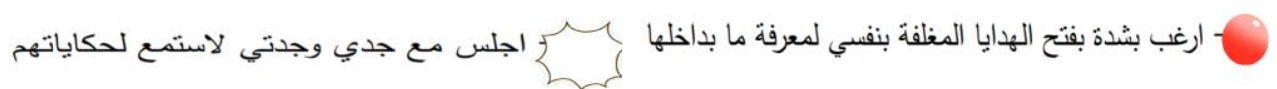




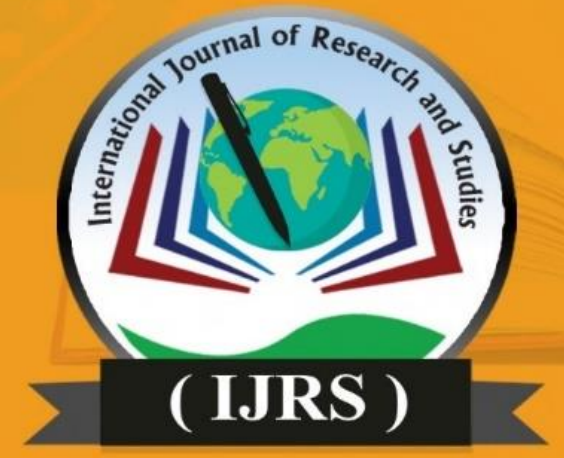

\section{International Journal of Educational and Psychological Research and Studies}

\section{( IJRS )}

3

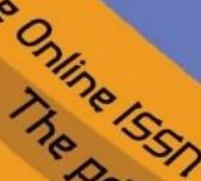

$$
\begin{aligned}
& 1 / 2 \pi / 2) \\
& \therefore\left(\frac{3}{3^{2}}\right) \\
& 5055
\end{aligned}
$$

